NASA/TM-2010-216344

\title{
Effect of High-Fidelity Ice Accretion Simulations on the Performance of a Full-Scale Airfoil Model
}

Andy P. Broeren and Michael B. Bragg

University of Illinois, Urbana, Illinois

Harold E. Addy, Jr.

Glenn Research Center, Cleveland, Ohio

Sam Lee

ASRC Aerospace Corporation, Cleveland, Ohio

Frédéric Moens

ONERA, Meudon, France

Didier Guffond

ONERA, Châtillon, France 


\section{NASA STI Program . . . in Profile}

Since its founding, NASA has been dedicated to the advancement of aeronautics and space science. The NASA Scientific and Technical Information (STI) program plays a key part in helping NASA maintain this important role.

The NASA STI Program operates under the auspices of the Agency Chief Information Officer. It collects, organizes, provides for archiving, and disseminates NASA's STI. The NASA STI program provides access to the NASA Aeronautics and Space Database and its public interface, the NASA Technical Reports Server, thus providing one of the largest collections of aeronautical and space science STI in the world. Results are published in both non-NASA channels and by NASA in the NASA STI Report Series, which includes the following report types:

- TECHNICAL PUBLICATION. Reports of completed research or a major significant phase of research that present the results of NASA programs and include extensive data or theoretical analysis. Includes compilations of significant scientific and technical data and information deemed to be of continuing reference value. NASA counterpart of peer-reviewed formal professional papers but has less stringent limitations on manuscript length and extent of graphic presentations.

- TECHNICAL MEMORANDUM. Scientific and technical findings that are preliminary or of specialized interest, e.g., quick release reports, working papers, and bibliographies that contain minimal annotation. Does not contain extensive analysis.

- CONTRACTOR REPORT. Scientific and technical findings by NASA-sponsored contractors and grantees.
- CONFERENCE PUBLICATION. Collected papers from scientific and technical conferences, symposia, seminars, or other meetings sponsored or cosponsored by NASA.

- SPECIAL PUBLICATION. Scientific, technical, or historical information from NASA programs, projects, and missions, often concerned with subjects having substantial public interest.

- TECHNICAL TRANSLATION. Englishlanguage translations of foreign scientific and technical material pertinent to NASA's mission.

Specialized services also include creating custom thesauri, building customized databases, organizing and publishing research results.

For more information about the NASA STI program, see the following:

- Access the NASA STI program home page at http://www.sti.nasa.gov

- E-mail your question via the Internet to help@ sti.nasa.gov

- Fax your question to the NASA STI Help Desk at 443-757-5803

- Telephone the NASA STI Help Desk at 443-757-5802

- Write to: NASA Center for AeroSpace Information (CASI) 7115 Standard Drive Hanover, MD 21076-1320 
NASA/TM-2010-216344

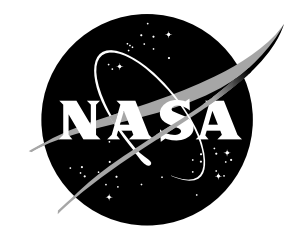

\section{Effect of High-Fidelity Ice Accretion Simulations on the Performance of a Full-Scale Airfoil Model}

Andy P. Broeren and Michael B. Bragg

University of Illinois, Urbana, Illinois

Harold E. Addy, Jr.

Glenn Research Center, Cleveland, Ohio

Sam Lee

ASRC Aerospace Corporation, Cleveland, Ohio

Frédéric Moens

ONERA, Meudon, France

Didier Guffond

ONERA, Châtillon, France

National Aeronautics and

Space Administration

Glenn Research Center

Cleveland, Ohio 44135 


\section{Acknowledgments}

The success of this collaborative research project is due to the combined efforts of many individuals at NASA, ONERA and University of Illinois. In particular, the staff of the ONERA F1 facility provided excellent support in the planning and execution of the aerodynamic testing. The ice simulations attached to the model during the testing were skillfully fabricated by the staff of the Aerospace Engineering Department Machine Shop at the University of Illinois. The authors at the University of Illinois were supported under NASA grant NCC3-1039 and ASRC Aerospace Corporation subcontract AS3304 from NASA Glenn Research Center. This support is gratefully acknowledged.

Level of Review: This material has been technically reviewed by technical management.

Available from

NASA Center for Aerospace Information 7115 Standard Drive

Hanover, MD 21076-1320
National Technical Information Service 5301 Shawnee Road Alexandria, VA 22312

Available electronically at http://gltrs.grc.nasa.gov 


\title{
Effect of High-Fidelity Ice Accretion Simulations on the Performance of a Full-Scale Airfoil Model
}

\author{
Andy P. Broeren and Michael B. Bragg \\ University of Illinois \\ Urbana, Illinois 61801 \\ Harold E. Addy, Jr. \\ National Aeronautics and Space Administration \\ Glenn Research Center \\ Cleveland, Ohio 44135 \\ Sam Lee \\ ASRC Aerospace Corporation \\ Cleveland, Ohio 44135 \\ Frédéric Moens \\ ONERA \\ Meudon, France F92190 \\ Didier Guffond \\ ONERA \\ Châtillon, France F92322
}

\begin{abstract}
The simulation of ice accretion on a wing or other surface is often required for aerodynamic evaluation, particularly at small scale or low-Reynolds number. While there are commonly accepted practices for ice simulation, there are no established and validated guidelines. The purpose of this article is to report the results of an experimental study establishing a high-fidelity, full-scale, iced-airfoil aerodynamic performance database. This research was conducted as a part of a larger program with the goal of developing subscale aerodynamic simulation methods for iced airfoils. Airfoil performance testing was carried out at the ONERA F1 pressurized wind tunnel using a 72-in. (1828.8-mm) chord NACA 23012 airfoil over a Reynolds number range of $4.5 \times 10^{6}$ to $16.0 \times 10^{6}$ and a Mach number range of 0.10 to 0.28 . The high-fidelity, ice-casting simulations had a significant impact on the aerodynamic performance. A spanwise-ridge ice shape resulted in a maximum lift coefficient of 0.56 compared to the clean value of 1.85 at $R e=15.9 \times 10^{6}$ and $M=0.20$. Two roughness and streamwise shapes yielded maximum lift values in the range of 1.09 to 1.28 , which was a relatively small variation compared to the differences in the ice geometry. The stalling characteristics of the two roughness and one streamwise ice simulation maintained the abrupt leading-edge stall type of the clean NACA 23012 airfoil, despite the significant decrease in maximum lift. Changes in Reynolds and Mach number over the large range tested had little effect on the iced-airfoil performance.
\end{abstract}

\section{Nomenclature}

$\begin{array}{ll}\alpha & \text { Airfoil angle of attack } \\ \alpha_{s t a l l} & \text { Stalling angle of attack, coincident with } C_{l, \text { max }} \\ c & \text { Airfoil chord length } \\ C_{d} & \text { Drag coefficient } \\ C_{l} & \text { Lift coefficient } \\ C_{l, \alpha} & \text { Lift-curve slope } \\ C_{l, m a x} & \text { Maximum lift coefficient, coincident with } \alpha_{\text {stall }} \\ C_{m} & \text { Quarter-chord pitching-moment coefficient } \\ k & \text { Ice-roughness height or thickness } \\ L W C & \text { Liquid Water Content } \\ M & \text { Freestream Mach number } \\ M V D & \text { Median Volumetric Diameter } \\ R e & \text { Reynolds number based on chord } \\ x & \text { Chordwise position along airfoil } \\ y & \text { Normal position from airfoil chord line }\end{array}$

\subsection{Introduction}

In many applications, simulation of the ice accretion geometry on a wing or other surface is required for aerodynamic evaluation. The measurement of aerodynamic performance from an aircraft or wing with actual ice accretions is very difficult and expensive and seldom a practical solution. Aircraft performance data with ice accreted in flight are available (Refs. 1 to 3), but limited, due to the cost and difficulty in acquiring these data. In flight, it is difficult to document the ice accretion geometry accurately 
where shedding often occurs. The accretions are difficult to attribute to a particular icing condition due to the natural atmospheric variations through which the airplane traverses. For accretions formed in an icing wind tunnel the inability to provide adequate instrumentation, nonuniformity of the cloud over the model, poor aerodynamic flow quality, and cost also make aerodynamic measurements difficult and rare. The most common way to acquire iced-airfoil and wing data is to use simulated, artificial ice accretions in a dry-air wind tunnel, or in flight. This process requires methods for developing the ice accretion simulations.

The best current technology for accurate ice accretion simulation is the mold and casting method developed at the NASA John H. Glenn Research Center (Ref. 4). In this method molds are made from an ice accretion generated in an icing wind tunnel, such as the NASA Glenn Icing Research Tunnel (IRT). From these molds, ice accretion castings are made that maintain the major features of the ice including the detailed surface roughness and the spanwise and chordwise variations. These castings are then instrumented to obtain high-fidelity aerodynamic data (Refs. 5 to 7 ) This is an expensive process and not practical in many situations, but does generate benchmark data for iced-airfoil and wing research.

While much of our understanding of ice accretion aerodynamics is anchored by cast ice simulation data, there have been very few studies employing full-scale ice accretion cast shapes aerodynamically tested at full-scale Reynolds and Mach number. The second FAA/NASA Tailplane Icing Program provides full-scale, cast-ice performance data at fullscale Reynolds and Mach number, but the ice shapes were applied to a fully three-dimensional tailplane model (Ref. 8). The NASA Modern Airfoils Program (Ref. 9) currently provides the best airfoil performance data set at flight Reynolds and Mach numbers, but due to size limitations in the NASA Langley Low-Turbulence Pressure Tunnel (LTPT) used for the aerodynamic testing, the ice accretions were obtained on a 36-in. (914.4-mm) chord airfoil. Ice accretion scaling methods can provide scaling of the gross ice shape for moderate scales (Ref. 10), but not of the roughness and ice shape details known to be aerodynamically important in some cases.

The simulation of ice accretions on airfoils and wings is needed or desirable for many applications. For flight or windtunnel tests of iced airfoils for certification or research, cast ice shapes are seldom available and lower-fidelity simulations are required. Computational methods must model ice on airfoils and wings and it is either impossible or impractical to model a full, rough 3-D accretion. Simpler geometries that accurately represent the key aerodynamic features are needed. Currently, there is only a limited understanding of how to accurately simulate the aerodynamic effect of ice accretion on lifting surfaces. Accurate simulations need to be based on an understanding of the fundamental flow physics for the simulation to be robust under a wide range of geometries and flow conditions. While there are commonly accepted practices supported by some research in this area, there are also remaining questions about the accuracy of such simulations (Ref. 11).

Many of these open issues are directly addressed in the "Airfoil Ice-Accretion Aerodynamics Simulation" research program sponsored by NASA and ONERA (Ref. 12). The completed program will result in validated scale model simulation methods that produce the essential aerodynamic features of the full-scale iced airfoil. This program, summarized in Section 2.0 below, required the development of a full-scale, iced-airfoil aerodynamic database for validation of the subscale model simulation methods. These data also provide, for the first time, aerodynamic data for high-fidelity ice simulations on a full-scale airfoil model at flight Reynolds number. The castings were fabricated from ice accretion testing conducted in the NASA IRT and were applied to the leading edge of a 72-in. chord (1828.8-mm) NACA 23012 airfoil model. Airfoil performance testing was carried out at the ONERA F1 pressurized wind tunnel over a Reynolds number range of $4.5 \times 10^{6}$ to $16.0 \times 10^{6}$ and a Mach number range of 0.10 to 0.28 . A total of six different ice accretion casting simulations were tested. The purpose of this article is to present these results.

\subsection{Background: Iced-Airfoil Aerodynamic Simulation}

The full-scale, high-fidelity, iced-airfoil aerodynamic database reported in this article was motivated by the problem of aerodynamic simulation of icing effects. Bragg et al. (Ref. 12) describe this six-phase research program. The plan included both subscale and full-scale ice accretion and aerodynamic testing. By using subscale testing whenever possible to minimize the expense of full-scale testing, and as a way to validate the scaled ice accretion simulations, an efficient and cost-effective program was developed. In Phase 1: Ice-Shape Classification, a review of the existing icedairfoil aerodynamic literature was performed in order to classify ice shapes according to their aerodynamic effects. The objective of Phase 2: Subscale Model Ice Accretion Testing was to obtain high-fidelity ice shapes for the subscale model having the characteristics developed in Phase 1. In Phase 3: Subscale Model Aerodynamic Testing, the high-fidelity ice shapes obtained in Phase 2 were used to develop aerodynamic simulation methods on the subscale model. The objective of Phase 4: Full-Scale Model Ice Accretion Testing was to obtain high-fidelity ice shapes for the full-scale model having the characteristics developed in Phase 1. In Phase 5: Full-Scale Model Aerodynamic Testing, the ice-shapes acquired in Phase 4 were used for aerodynamic testing on the full-scale model to obtain a benchmark data set for the validation of subscale simulation methods. Finally, in Phase 6: Simulation Validation Testing, the methods developed in Phase 3 were 
used to scale and simulate the full-scale ice shapes for testing on the subscale model at lower Reynolds number. The objective of this phase was to "close the loop" by using the subscale model to reproduce the aerodynamic effects of the ice shapes tested on the full-scale model at high Reynolds number. Each phase of this research program is summarized below.

\subsection{Phase 1: Ice-Shape Classification}

The first phase of the research was to develop ice-shape classifications based upon the iced-airfoil aerodynamics. Bragg et al. (Refs. 13 and 14) defined four categories of ice accretion: roughness, horn, streamwise, and spanwise ridge. Roughness is defined as the type of ice accretion that affects the boundary-layer transition process and extracts momentum from the boundary layer. This leads to premature trailing-edge separation and increased drag and reduced lift. Specific examples of roughness and the other types of ice are discussed in Section 3.0. Horn ice is a larger accretion that has at least one protrusion orientated at a significant angle to the oncoming flow and is located in the airfoil leading-edge region such that the stagnation point is on the ice accretion. This results in a large separation bubble aft of the accretion that governs the aerodynamics. The separation bubble significantly increases the drag and reduces the stalling angle of attack and maximum lift. Streamwise ice is more conformal to the leading edge and thus does not result in a large separated flow region. There may be localized separation on the scale of the ice shape owing to discontinuities at the ice/airfoil junction. The boundary layer is significantly affected by the ice, resulting in earlier transition and trailingedge separation. Spanwise-ridge ice is characterized by a large separation bubble aft of the ridge, but differs from horn ice in that ridges are located downstream of the leading edge. The airfoil upstream of the ice ridge is smooth such that the stagnation point is not located on the ice accretion, and a boundary layer develops upstream. This leads to an additional separation bubble upstream of the ridge thus making the threedimensional characteristics of the ridge more important than in the horn ice case. It is important to note that there is often overlap among these classifications and that real ice accretion could be characterized by a combination of these descriptions. However, this type of flowfield-based understanding is useful from the simulation perspective. Thus, it was this understanding that guided the selection of full-scale ice accretions for the aerodynamic testing presented in this article.

\subsection{Phase 2: Subscale Model Ice Accretion Testing}

The objective of this phase was to obtain high-fidelity ice shapes having the characteristics of the four types described in Phase 1. To obtain these shapes, a subscale, 18-in. (457.2-mm) chord NACA 23012 airfoil model was subjected to simulated, in-flight icing conditions in the NASA IRT. The icing conditions were selected to produce accretions representative of the four classifications. Molds were made of selected ice accretions that were used to develop castings (Ref. 4) for aerodynamic testing in Phase 3. Blumenthal (Ref. 15) provides more details and results of this phase of the program.

\subsection{Phase 3: Subscale Model Aerodynamic Testing}

The objective of this phase was to develop simulation methods to reproduce the aerodynamics of the iced-airfoil. Each of the four classifications has different fundamental aerodynamics. If techniques can be developed to simulate these four shapes, then most ice accretions can be simulated. A variety of simulation methods already exist in the literature and in practice and these were categorized for subscale testing. The simulation categories considered were: 3-D castings, 2-D smooth and simple-geometry. To account for roughness associated with ice accretion, distributed grit-type roughness may be added to the non-casting simulation methods. The casting was considered to be the highest fidelity simulation. It is a benchmark for aerodynamic testing that the other lowerfidelity simulation methods are evaluated against.

Numerous experimental trials have been conducted with the ice accretions obtained in Phase 2 to investigate the effectiveness of the various simulations and quantify the associated accuracy. These results are documented in several papers (Refs. 16 to 20) and are summarized here. The combined results indicate that different methods should be used to best represent the aerodynamics of the iced-airfoil according to the different classifications of ice accretion. In the horn-ice case, the 2-D smooth and simple-geometry simulations were nearly equal in effectiveness owing to the dominance of the separation bubble flowfield. The addition of roughness reduced the simulation fidelity when compared to the casting results. In contrast, the addition of roughness to the 2-D simulations was required to obtain the best agreement in performance with the casting configuration for the streamwise ice accretion. In this case, the size and concentration had significant effects such that these parameters should be taken into account. The performance effects of the spanwise-ridge ice accretion was best reproduced by the 2-D smooth simulation. The spanwise-ridge shape did not result in a large, closed-two dimensional separation bubble and the resulting flowfield was highly three dimensional with evidence of trailing-edge separation. These effects complicated the ability to simulate the aerodynamics of the iced airfoil with lowerfidelity geometries.

\subsection{Phase 4: Full-Scale Model Ice Accretion Testing}

The objective of this phase of the program was to obtain high-fidelity ice shapes in each of the four categories on a full- 
scale airfoil. Since this effort was designed to develop subscale simulation methods, it was important to have a set of benchmark data and firm knowledge of the full-scale phenomena. This information provides validation data for both the subscale testing and simulation methods developed. In order to obtain full-scale aerodynamic effects information for the four classifications of ice, accurate representations of the ice were needed. Therefore, a full-scale, 72-in. (1828.8-mm) chord, NACA 23012 airfoil, ice accretion model was built and tested in the NASA IRT. This effort provided the full-scale, reference ice shapes for the program. Molds were made of selected ice accretions and were used to develop castings (Ref. 4) that were used for the full-scale aerodynamic testing and are described in Section 3.0.

\subsection{Phase 5: Full-Scale Model Aerodynamic Testing}

In this phase, aerodynamic testing was conducted to establish a set of high-fidelity benchmark data useful for the development of simulation methods at smaller scale. Airfoil performance testing was performed in a pressurized wind tunnel. A total of six different ice accretion casting simulations were tested. As was the case for the subscale testing, ice shapes were selected according to the four classifications developed in Phase 1. In contrast to the subscale testing, only the high-fidelity ice casting simulations were tested on the full-scale model. This approach increased the number of different ice shapes that could be tested with the given amount of tunnel time. The purpose of this article is to present these results.

\subsection{Phase 6: Simulation Validation Testing}

In this final phase of the program, the ice shapes selected for the full-scale aerodynamic testing were scaled and simulated for testing on the subscale model. Lower-fidelity simulations of the full-scale ice shapes were developed and tested on the quarter-scale model at low-Reynolds number $\left(1.8 \times 10^{6}\right)$. Busch et al. (Ref. 21) quantified the accuracy of the subscale simulations against the full-scale data reported in this article. For horn ice, it was determined that accurately representing the height, angle, and location of the uppersurface horn using a 2-D smooth simulation provided an accurate representation of $C_{l, \max }$. Similar results were obtained for spanwise-ridge ice - the simulation of geometric details of the ice shape including roughness had only minor effects on the iced-airfoil $C_{l, \max }$. For roughness and streamwise ice, it was found that geometric scaling of the roughness height tended to cause unrepresentatively large penalties to $C_{l, \max }$ and $C_{d}$ when the roughness was applied at high concentration. Reducing roughness concentration would decrease these penalties, but at this time no accurate method exists for measuring roughness concentration on an ice accretion. Therefore, modeling both roughness height and concentration is important in subscale iced-airfoil simulation for some types of ice.

\subsection{Experimental Methods}

All of the aerodynamic testing reported here for Phase 5 was performed at the ONERA F1 full-scale, pressurized windtunnel facility (Ref. 22). The closed-return wind tunnel has a test-section measuring 138-in. (3500-mm) high by 177-in. (4500-mm) wide by 433 -in. (11000-mm) long. The maximum test section Mach number is 0.36 and the maximum stagnation pressure is 57 psia ( 3.85 bar). The unit Reynolds number can be varied up to a maximum of $6.0 \times 10^{6} / \mathrm{ft}$ at $\mathrm{Mach}=0.23$. Total temperature is maintained via a heat exchanger located in the second diffuser downstream of the fan. The fan operates at constant speed while the test section Mach number is controlled by adjusting the pitch of the blades. The test-section inlet flow is conditioned through a 7.18-to-1 contraction containing honeycomb flow straightener and three turbulence reduction screens.

The 72-in. (1828.8-mm) chord NACA 23012 airfoil model was mounted vertically in the test section as shown in Figure 1. The model span was 137.48-in. (3492-mm) and was mounted in the floor force balance. Small gaps between the bottom of the model and the test-section floor as well as the top of the model and the test-section ceiling were maintained so as not to cause mechanical hysteresis in the force-balance measurements. The model had a main chordwise row of 72 pressure taps located at 43 percent span measured from the test-section floor (cf. Fig. 1). In addition, there was a row of 20 taps oriented spanwise at $x / c=0.70$ on the upper surface. The model was designed and built with full-span removable, interchangeable, leading-edge sections. The baseline leading edge had the clean NACA 23012 profile, while the alternate leading edge had a truncated nose geometry. The latter design facilitated mounting of the various ice-shape casting simulations. Accommodations were also made in the pressure tapping to allow for rapid connection of pressure instrumentation in the cast ice shapes. Also shown in Figure 1 is the wake rake located one chord length downstream of the model trailing edge. The wake rake had 100 stagnation pressure probes spaced 0.79 -in. $(20-\mathrm{mm})$ apart and was located at a fixed spanwise station at 57 percent span above the test-section floor.

Data acquisition runs were performed in angle of attack sweeps for increasing and then decreasing angle of attack at a constant sweep rate of $0.1 \% \mathrm{sec}$. Data were also acquired at fixed angle of attack for selected angles over the range of the sweep and repeat runs were performed to ensure data precision. The data shown in this paper are for increasing angle of attack sweeps and have been averaged to the nearest $0.5^{\circ}$ in post-processing. The averaging method divided the data into $0.5^{\circ}$ bins and averaged the results. For example, data from $\alpha=2.75^{\circ}$ to $3.25^{\circ}$ were average to create a data point 

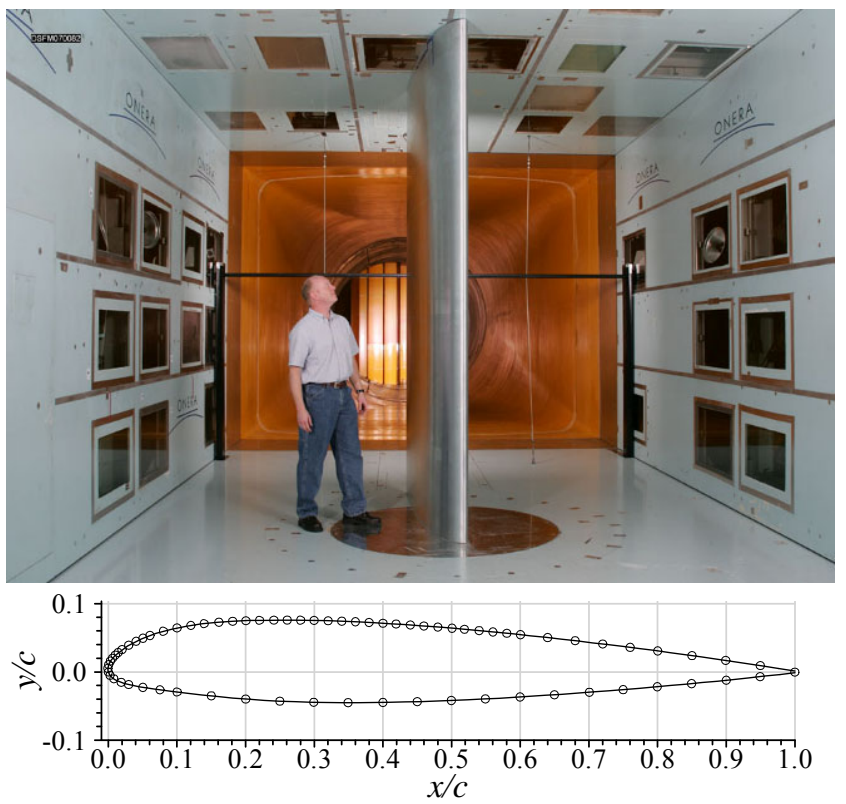

Figure 1.-Photograph of NACA 23012 airfoil model installed in ONERA F1 wind-tunnel test section and model pressure tap layout.

close to $\alpha=3.0^{\circ}$ The actual angle of attack value was the arithmetic mean of the angles of attack collected in that bin. During the sweeps, data were acquired from the force balance and tunnel conditions analog transducers. The model surface, test-section sidewall, and wake-rake pressures were acquired using an electronically scanned pressure system. The acquisition of these data were synchronized in time corresponding to the angle of attack sweep rate. Lift and pitching-moment coefficients were calculated from the force balance and from the integration of the surface pressure measurements. Good agreement between the integratedpressure data and the force-balance data were obtained. In this paper, the lift and pitching moment data reported for the clean configuration were obtained from the surface pressures while the data reported for the iced configurations were obtained from the force balance. The force balance data are reported because, in many cases, the stall of the iced-airfoil configurations was characterized by unsteady flow. The available signal conditioning for the force-balance data allowed for more effective filtering of these unsteady effects. Drag coefficient was calculated from the wake pressures using standard momentum-deficit methods and these values are reported in this paper for all configurations. The performance coefficients were corrected for wind-tunnel wall effects using the methods of Allen and Vincenti (Ref. 23). The angle of attack sweeps were performed for a large range of Reynolds numbers and Mach numbers as shown in Table 1. The matrix was designed to isolate the independent effects of these parameters. Therefore, Reynolds numbers variations were performed at constant Mach numbers of 0.10 and 0.20 while a Mach number variation was performed at a constant nominal Reynolds number of $12 \times 10^{6}$. Due to operational constraints, the Reynolds number was not maintained entirely constant for each of these conditions, and therefore Table 1 indicates the variation over the course of the entire test campaign.

TABLE 1.-MATRIX OF REYNOLDS AND MACH NUMBER CONDITIONS

\begin{tabular}{|l|c|c|c|}
\hline \multicolumn{1}{|c|}{$\begin{array}{c}\text { Reynolds } \\
\text { number range }\end{array}$} & \multicolumn{3}{|c|}{ Mach number } \\
\cline { 2 - 4 } & 0.10 & 0.20 & 0.28 \\
\hline $4.5 \times 10^{6}$ to $4.6 \times 10^{6}$ & $\mathrm{X}$ & & \\
$8.0 \times 10^{6}$ to $9.1 \times 10^{6}$ & $\mathrm{X}$ & $\mathrm{X}$ & \\
$12.0 \times 10^{6}$ to $12.3 \times 10^{6}$ & $\mathrm{X}$ & $\mathrm{X}$ & $\mathrm{X}$ \\
$15.8 \times 10^{6}$ to $16.0 \times 10^{6}$ & & $\mathrm{X}$ & \\
\hline
\end{tabular}

The experimental uncertainty in the performance coefficients was estimated using the methods of Kline and McClintock (Ref. 24) and Coleman and Steele (Ref. 25) for 20:1 odds. Table 2 lists these uncertainties for both integratedpressure and force-balance measurements, before the wall corrections were applied. The values were calculated based upon the clean model configuration at $R e=8.1 \times 10^{6}$ and $M=$ 0.20 . The uncertainties are expected to be identical for the iced-model configurations. The absolute uncertainties in Table 2 are inversely proportional to the dynamic pressure (except for $\alpha$ ). This condition was selected because it corresponds to the average dynamic pressure over the range of conditions (Table 1). Therefore, conditions having lower dynamic pressure would have slightly larger uncertainties while conditions with higher dynamic pressure would have slightly lower uncertainties. All of these uncertainties were acceptable for the purposes of this investigation. The relative uncertainty in $C_{m}$ (both pressure and balance) seems large for this example because of the small reference value. For cases where the $C_{m}$ values were larger, e.g. in the iced-airfoil case, the absolute uncertainty would be similar, therefore resulting in a lower relative uncertainty. This is also the case for the uncertainty in drag coefficient. Several repeat runs were performed for both clean and iced configurations and the runto-run variations in the coefficients were much smaller than the uncertainties listed in Table 2. The good agreement between the integrated-pressure and force-balance data provided further assurances of data quality.

TABLE 2.-ESTIMATED EXPERIMENTAL UNCERTAINTIES.

\begin{tabular}{|l|c|c|c|}
\hline $\begin{array}{c}\text { Aerodynamic } \\
\text { quantity }\end{array}$ & $\begin{array}{c}\text { Reference } \\
\text { value }\end{array}$ & $\begin{array}{c}\text { Absolute } \\
\text { uncertainty }\end{array}$ & $\begin{array}{c}\text { Relative } \\
\text { uncertainty }\end{array}$ \\
\hline$\alpha$ & $8.01^{\circ}$ & $\pm 0.02^{\circ}$ & $\pm 0.25 \%$ \\
$C_{l}$ Balance & 1.095 & \pm 0.010 & $\pm 0.93 \%$ \\
$C_{m}$ Balance & -0.0144 & \pm 0.00071 & $\pm 4.9 \%$ \\
$C_{p}$ & -1.057 & \pm 0.015 & $\pm 1.41 \%$ \\
$C_{l}$ Pressure & 1.096 & \pm 0.0070 & $\pm 0.64 \%$ \\
$C_{m}$ Pressure & -0.0148 & \pm 0.0024 & $\pm 16.5 \%$ \\
$C_{d}$ Wake & 0.0086 & \pm 0.00048 & $\pm 5.5 \%$ \\
\hline
\end{tabular}


A total of six ice accretion simulations were tested. Using the ice accretion classifications developed by Bragg et al. (Refs. 13 and 14) there was one horn shape, one spanwiseridge shape, two roughness shapes and two streamwise shapes. The casting simulations were fabricated from ice accretion moldings acquired during Phase 4 of the program as described in Section 2.0 and in more detail by Bragg et al. (Ref. 12) Table 3 summarizes the icing conditions associated with the ice accretions selected for aerodynamic testing. These ice accretions are documented in Figures 2 to 7 . The horn shape in Figure 2 shows the classic upper-surface horn typical of this glaze-type accretion. The streamwise shape in Figure 3 is more conformal to the leading-edge radius with a smooth zone on the nose followed by downstream rime feather roughness. The glaze roughness in Figure 4 had a smooth zone in the stagnation region followed by large roughness downstream. The spanwise-ridge shape in Figure 5 was formed by applying a heater mat to the model leading edge. The heat input and icing conditions were adjusted to accrete the upper and lower surface ridges shown in Figure 5. The streamwise shape in Figure 6 was selected for aerodynamic testing because it had a more "pointed" geometry at the leading edge and was less conformal to the surface than the other streamwise shape (Fig 3). The remaining roughness case in Figure 7 was formed in cold conditions resulting in very fine rime feathers that were very different in size and distribution from the glaze roughness case in Figure 4.

For each ice accretion a set of casting simulations were fabricated for aerodynamic testing. The castings were made from a hard two-part, polyurethane-type material of very low viscosity required to flow into the intricate details of the ice molds. The moldings of the ice accretions were limited to a span of 15 -in. (381-mm) at the center of the IRT model. This was sufficient length to reproduce the spanwise variation in all of the ice accretion geometries. Therefore, multiple sections of casting were fabricated for each ice shape to cover the 137.48in. (3492-mm) span of the NACA 23012 model. A total of 10 sections were used, each having a finished length of 13.75-in. $(349.3-\mathrm{mm})$. The sections were bolted on to the alternate leading edge of the model and the interfaces were sealed with silicone. A completed installation is shown in Figure 8. One casting section was instrumented with static pressure taps. This was located at the same spanwise station as the main chordwise row on the model (43 percent span measured from the test-section floor). The orifices were drilled directly into the casting and located in areas conducive to good surface static pressure measurements based upon previous research (Ref. 15). The number of pressure taps on the entire removable section ranged from 29 to 36 with some ice shapes requiring higher resolution. The pressure orifice locations are indicated in the tracings of Figures 2 to 7 . These tracings were obtained from the casting of the ice shape instead of from the tunnel ice accretion. This was accomplished by fabricating an additional 15 -in. casting section that was cut at the tap location for tracing.

\subsection{Results and Discussion}

\subsection{Clean Airfoil Aerodynamics}

The NACA 23012 airfoil model was tested in the baseline configuration to establish the clean performance over the given range of Reynolds and Mach numbers. Overall, the clean-airfoil results followed classic airfoil behavior and compared favorably with existing data. Validation of the clean performance was established primarily by comparison of the present data with archival data and XFOIL results for the NACA 23012 airfoil section. An example of this comparison is shown in Figure 9 for approximately matched Reynolds and Mach number conditions. Broeren et al. (Ref. 5), performed a more recent test of a 36-in. chord NACA 23012 airfoil in the NASA LTPT at $R e=7.5 \times 10^{6}$ and $M=0.21$. Abbott and von Doenhoff (Ref. 26) tested a 24-in. chord NACA 23012 airfoil also at LTPT. These data are for $R e=8.8 \times 10^{6}$ and $M<0.17$ (the exact Mach number was not given). The lift coefficient versus angle of attack trend shows very good agreement. The Broeren et al. (Ref. 5) data had a slightly higher slope for angles of attack preceding the stall, while the Abbott and von Doenhoff (Ref. 26) data had a slightly lower slope for negative angles of attack. The sharp stall of the clean airfoil is indicative of leading-edge stall. For this stall type, boundarylayer separation occurs near the leading edge without subsequent reattachment, resulting in separated flow over the airfoil and the significant decrease in lift (Ref. 27). The agreement in maximum lift coefficient was very good and well within the range of experimental uncertainty, potential variations in wall-correction methods, and manufacturing

TABLE 3.-ICE ACCRETIONS SELECTED FOR AERODYNAMIC TESTING

\begin{tabular}{|l|c|c|c|c|c|c|c|c|}
\hline $\begin{array}{c}\text { Ice } \\
\text { classification }\end{array}$ & $\begin{array}{c}\text { Run } \\
\text { no. }\end{array}$ & $\begin{array}{c}\text { Airspeed } \\
\text { knots }\end{array}$ & $\begin{array}{c}\alpha \\
\text { deg. }\end{array}$ & $\begin{array}{c}M V D \\
\mu \mathrm{m}\end{array}$ & $\begin{array}{c}L W C \\
\mathrm{~g} / \mathrm{m}^{3}\end{array}$ & $\begin{array}{c}\text { Total } \\
\text { temperature } \\
{ }^{\circ} \mathrm{F} /{ }^{\circ} \mathrm{C}\end{array}$ & $\begin{array}{c}\text { Static } \\
\text { temperature } \\
{ }^{\circ} \mathrm{F} /{ }^{\circ} \mathrm{C}\end{array}$ & $\begin{array}{c}\text { Spray } \\
\text { time } \\
\text { min. }\end{array}$ \\
\hline Horn & EG1164 & 175 & 5.0 & 20 & 0.85 & $28.0 /-2.2$ & $20.8 /-6.2$ & 11.3 \\
Streamwise 1 & EG1162 & 150 & 2.0 & 30 & 0.55 & $-8.0 /-22.2$ & $-13.5 /-25.3$ & 10.0 \\
Roughness 1 & EG1126 & 200 & 2.0 & 20 & 0.50 & $28.0 /-2.2$ & $18.6 /-7.4$ & 2.0 \\
Spanwise Ridge & EG1159 & 150 & 1.5 & 20 & 0.81 & $20.0 /-6.7$ & $14.8 /-9.6$ & 15.0 \\
Streamwise 2 & EG1125 & 200 & 2.0 & 15 & 0.30 & $4.0 /-15.6$ & $-5.3 /-20.7$ & 20.0 \\
Roughness 2 & EG1134 & 200 & 2.0 & 40 & 0.55 & $4.0 /-15.6$ & $-5.3 /-20.7$ & 2.0 \\
\hline
\end{tabular}



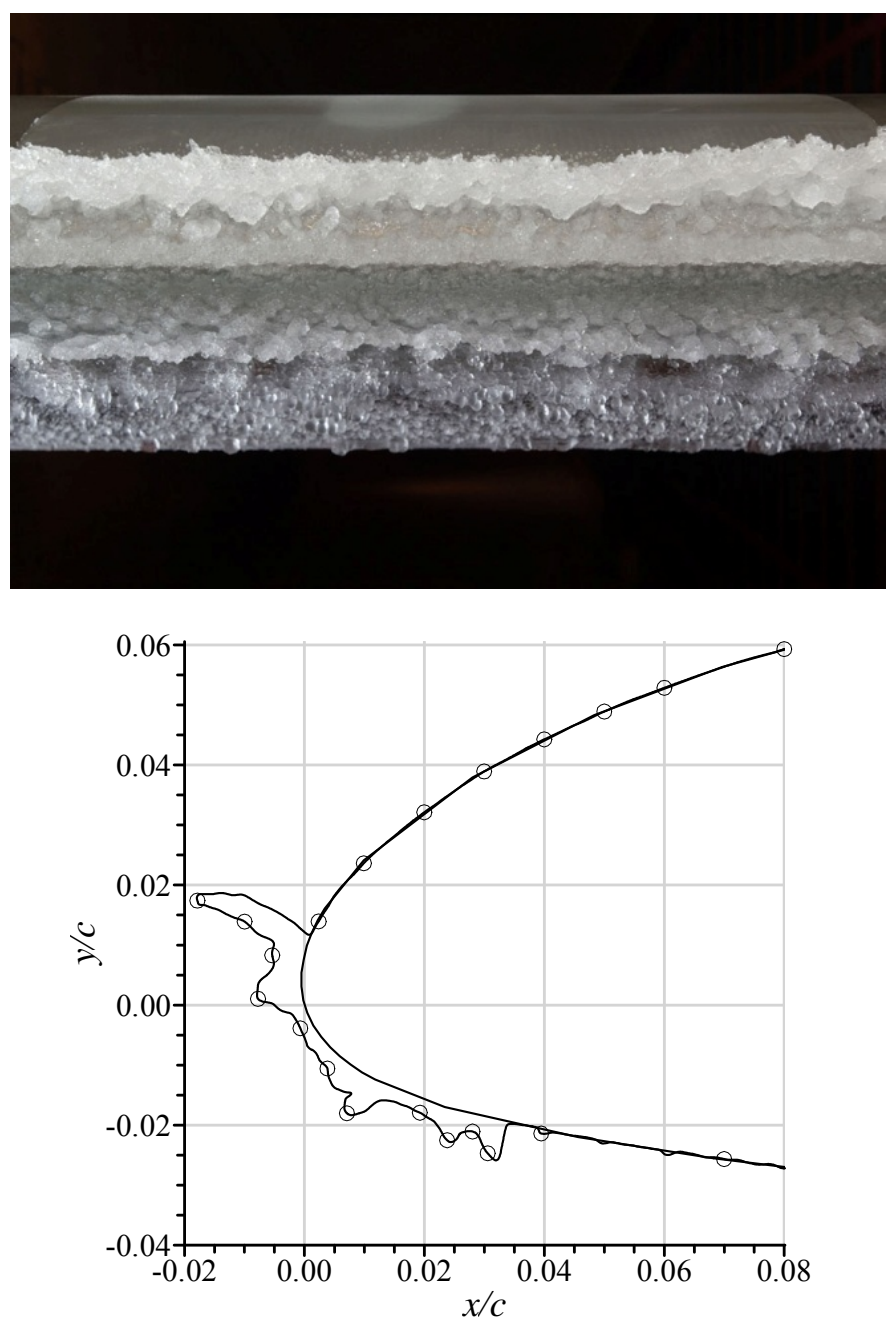

Figure 2.-Tracing and photograph of horn shape EG1164. Tracing taken from ice casting used for aerodynamic testing with pressure orifice locations indicated by open circles.
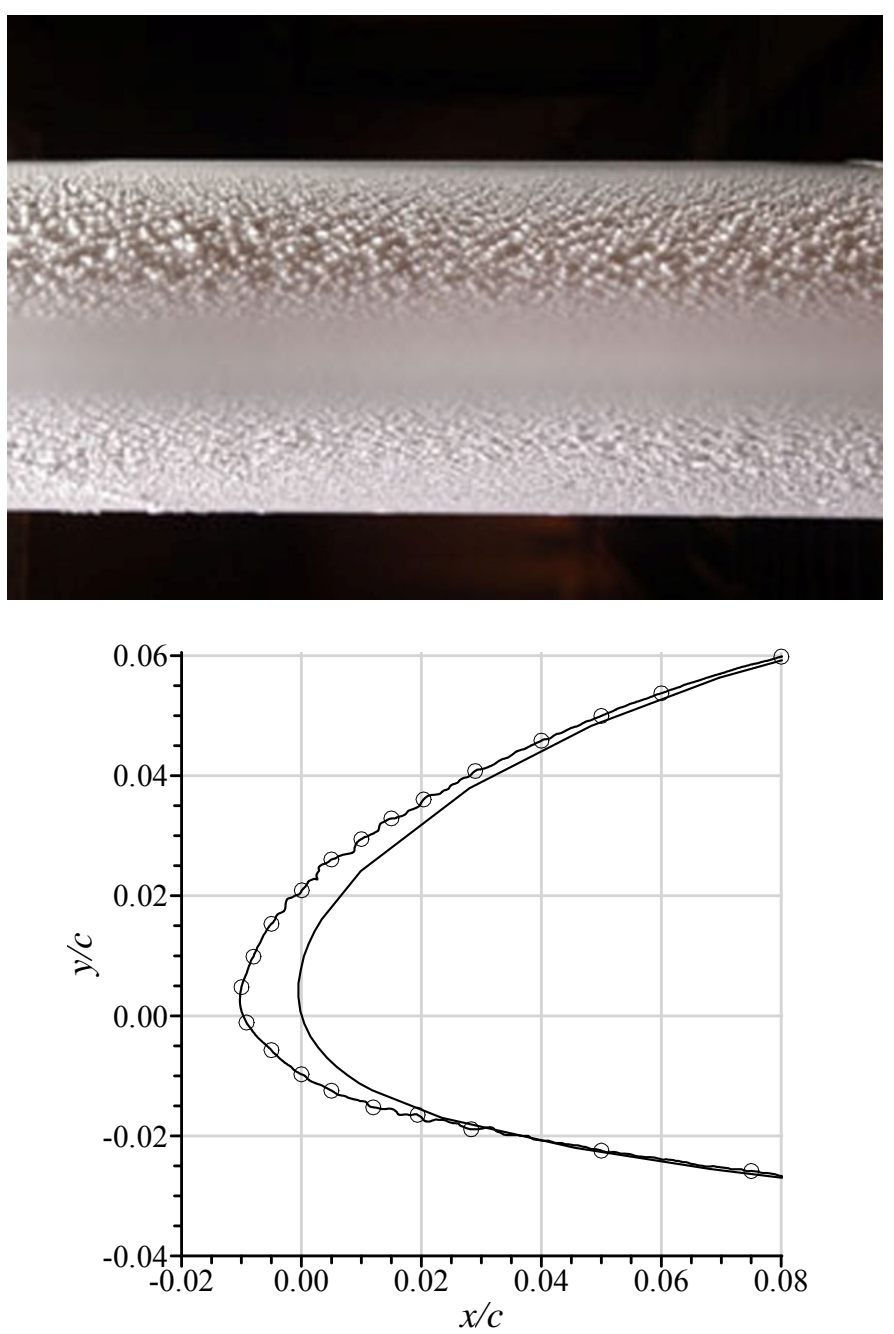

Figure 3.-Tracing and photograph of streamwise shape 1 EG1162. Tracing taken from ice casting used for aerodynamic testing with pressure orifice locations indicated by open circles. 

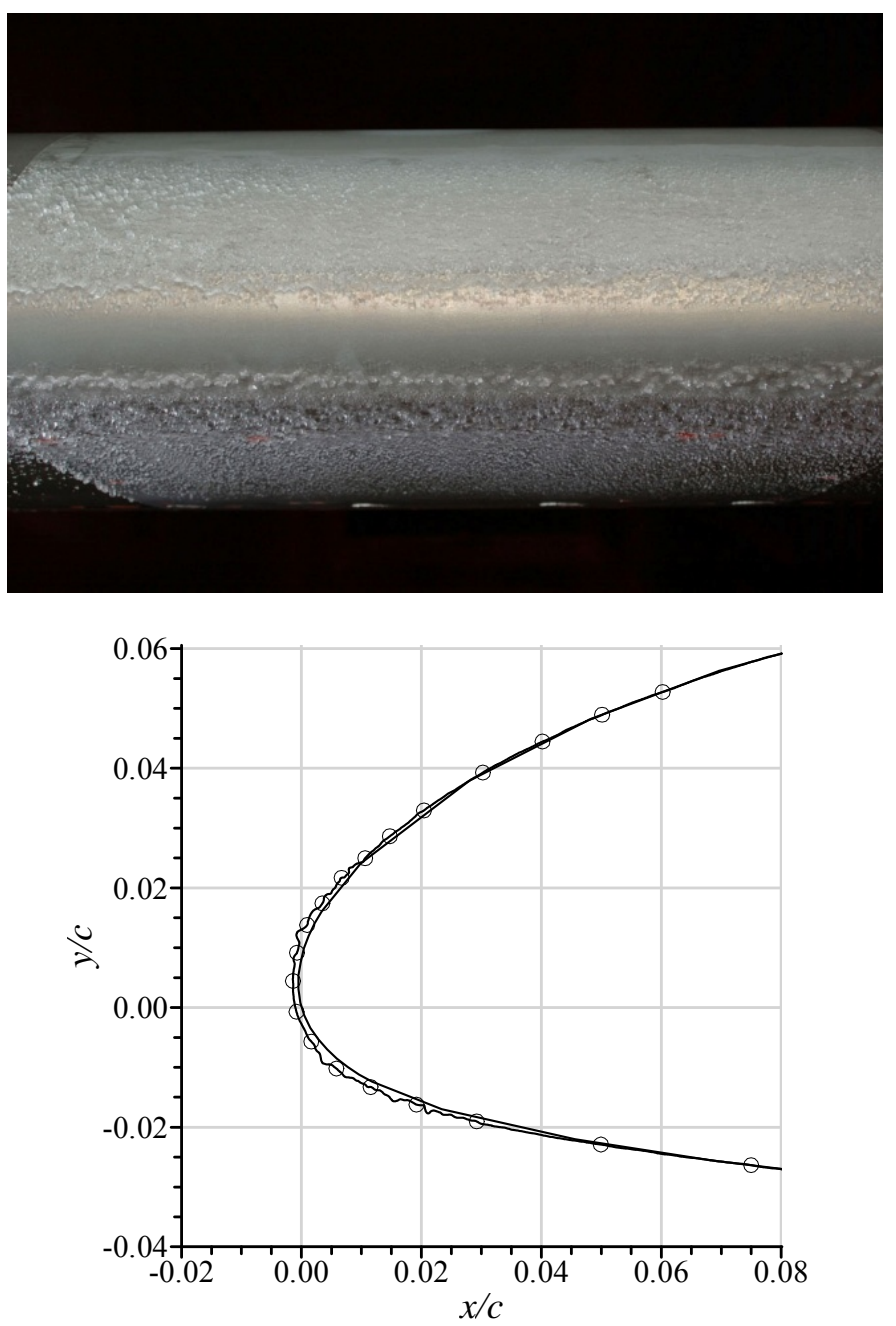

Figure 4.-Tracing and photograph of roughness shape 1 EG1126. Tracing taken from ice casting used for aerodynamic testing with pressure orifice locations indicated by open circles.
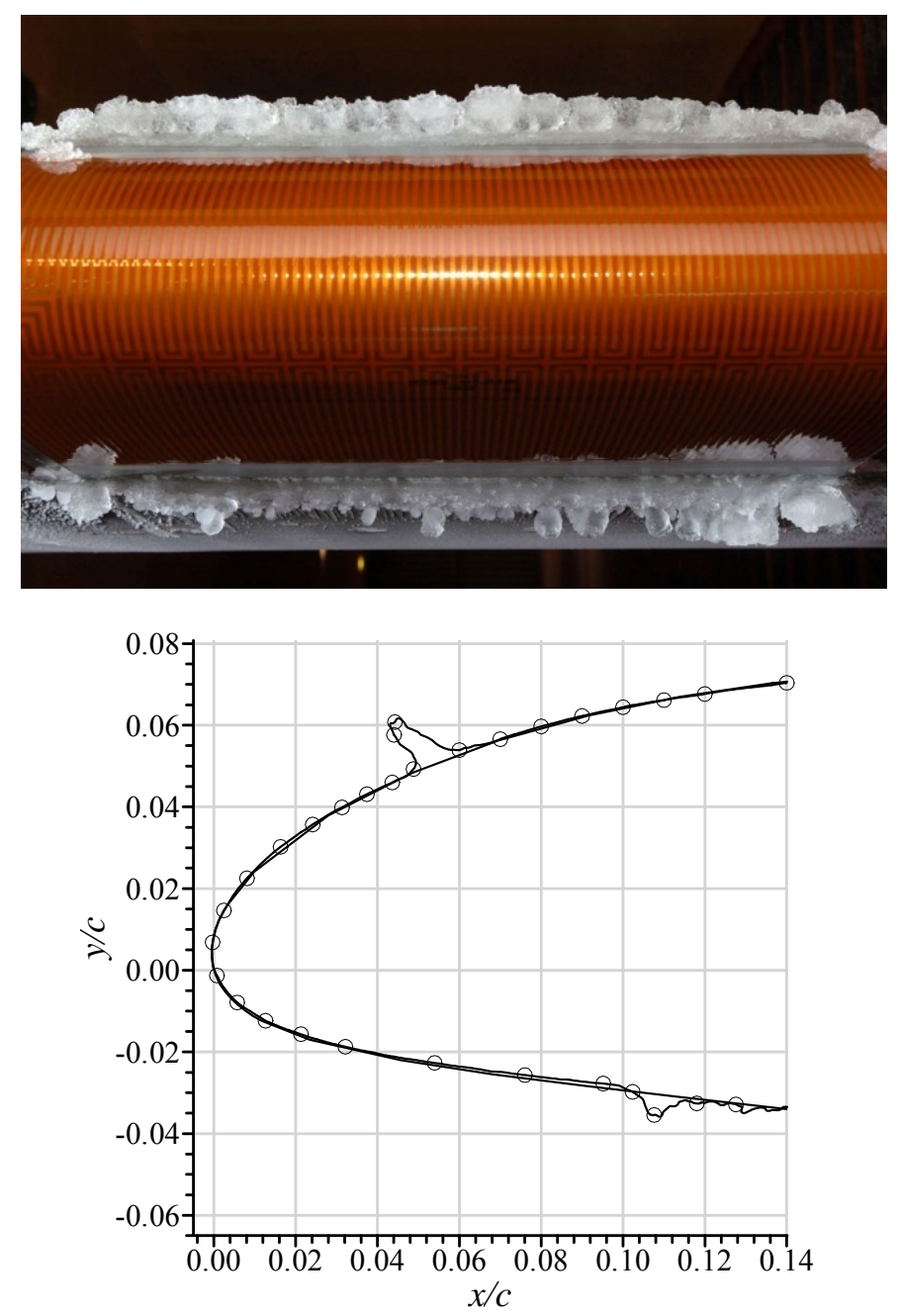

Figure 5.-Tracing and photograph of spanwise-ridge shape EG1159. Tracing taken from ice casting used for aerodynamic testing with pressure orifice locations indicated by open circles. 

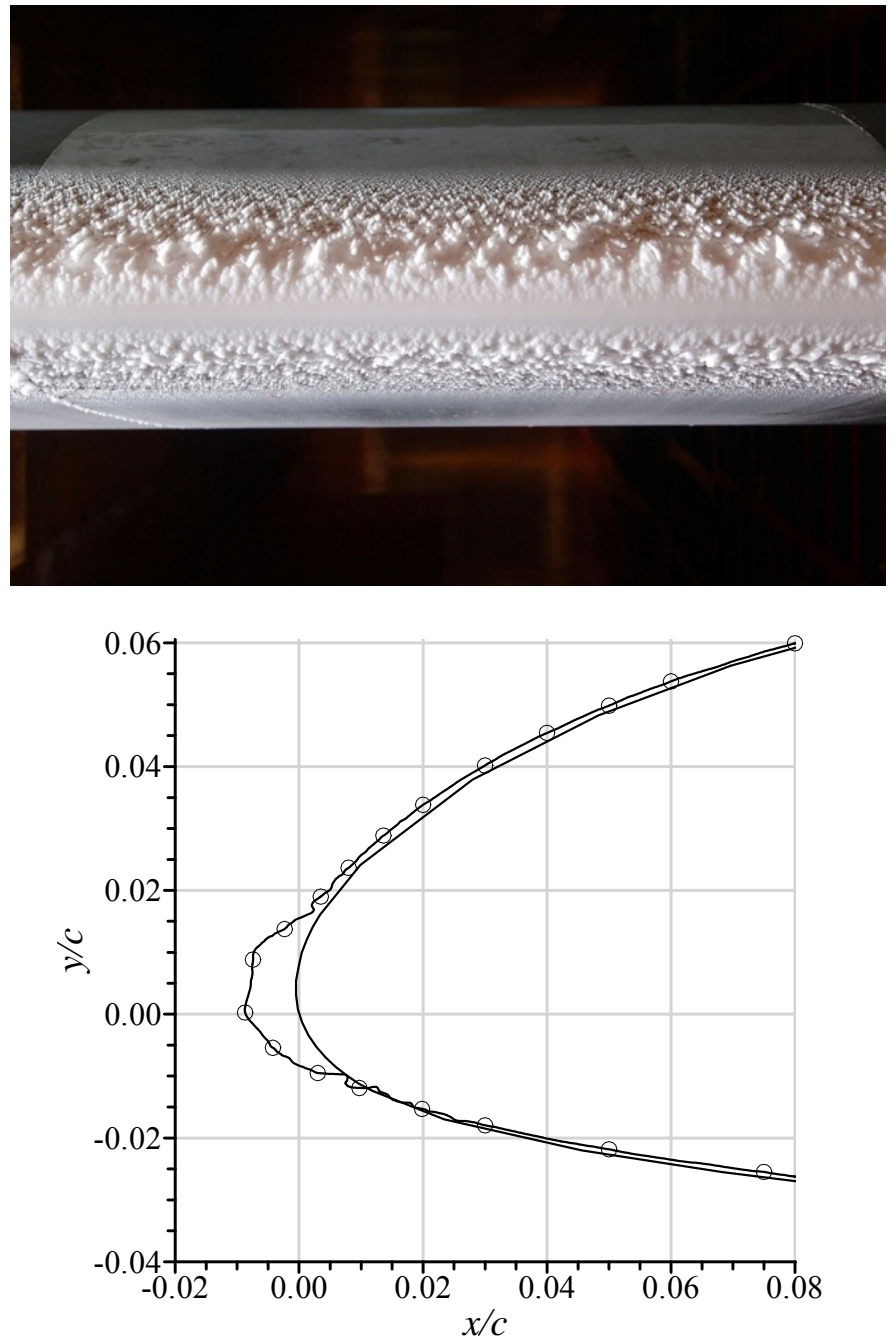

Figure 6.-Tracing and photograph of streamwise shape 2 EG1125. Tracing taken from ice casting used for aerodynamic testing with pressure orifice locations indicated by open circles.
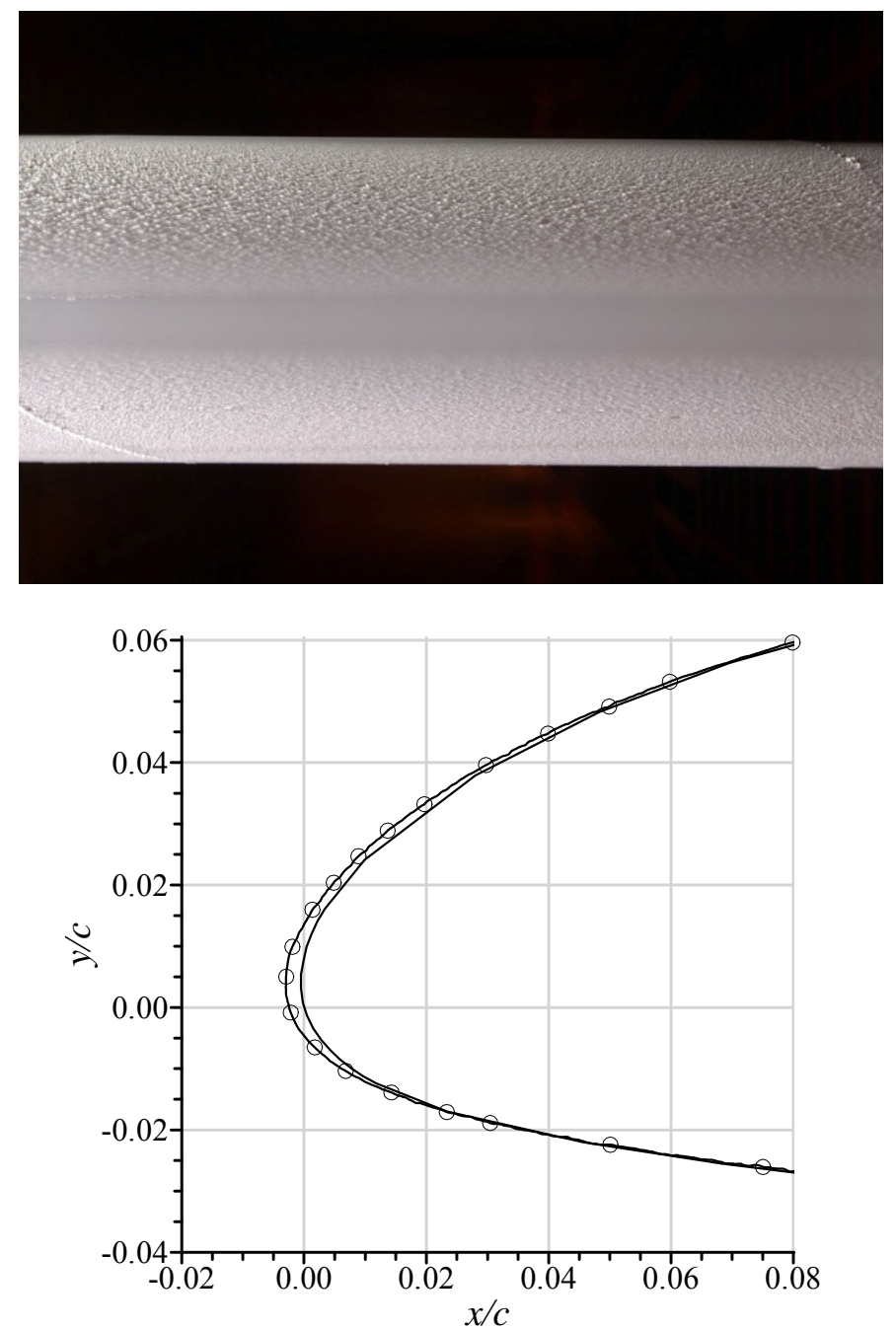

Figure 7.-Tracing and photograph of roughness shape 2 EG1134. Tracing taken from ice casting used for aerodynamic testing with pressure orifice locations indicated by open circles. 


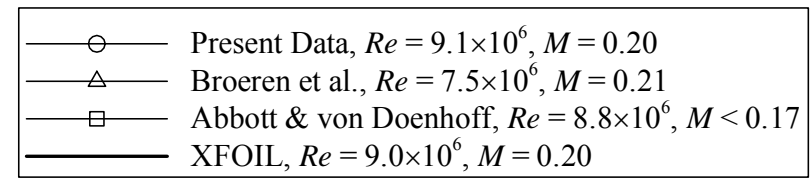

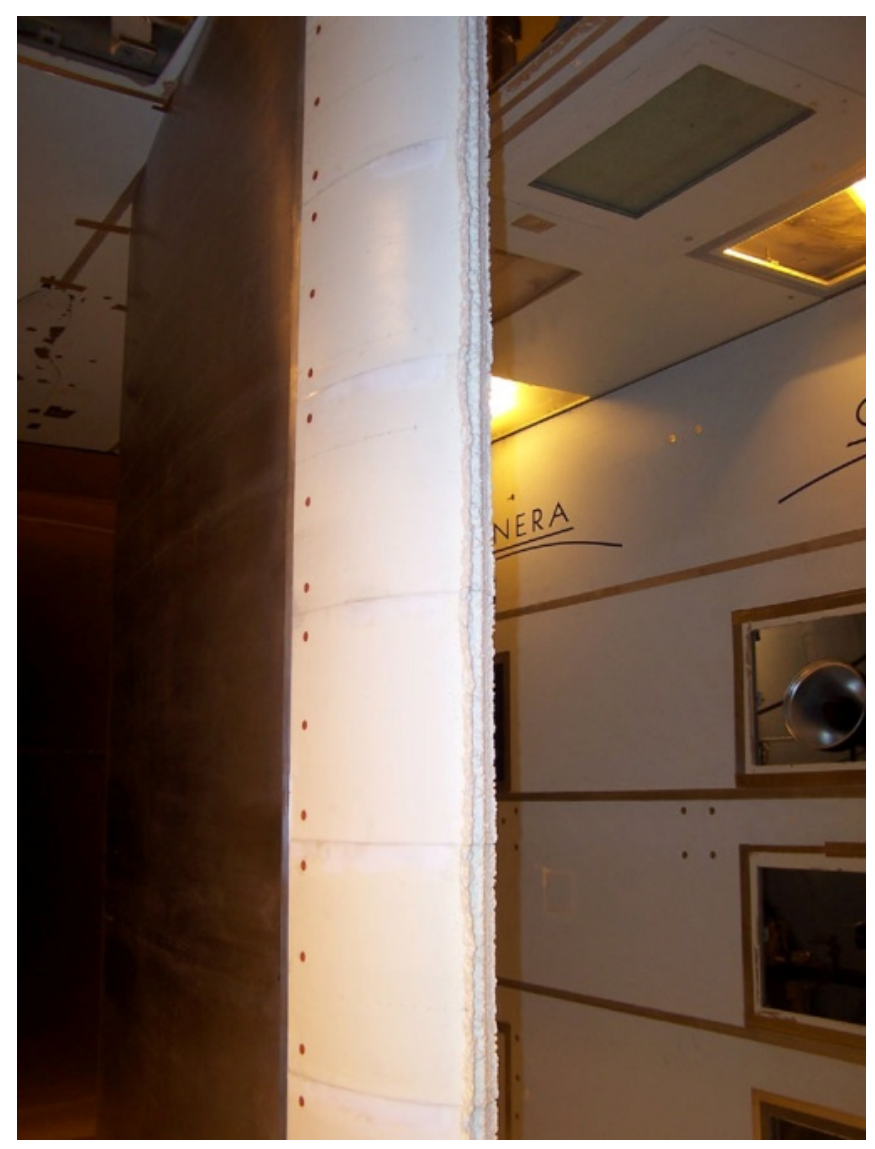

Figure 8.-Completed installation of horn shape EG1164 casting sections on the leading edge of the NACA 23012 airfoil model (upper-surface view).
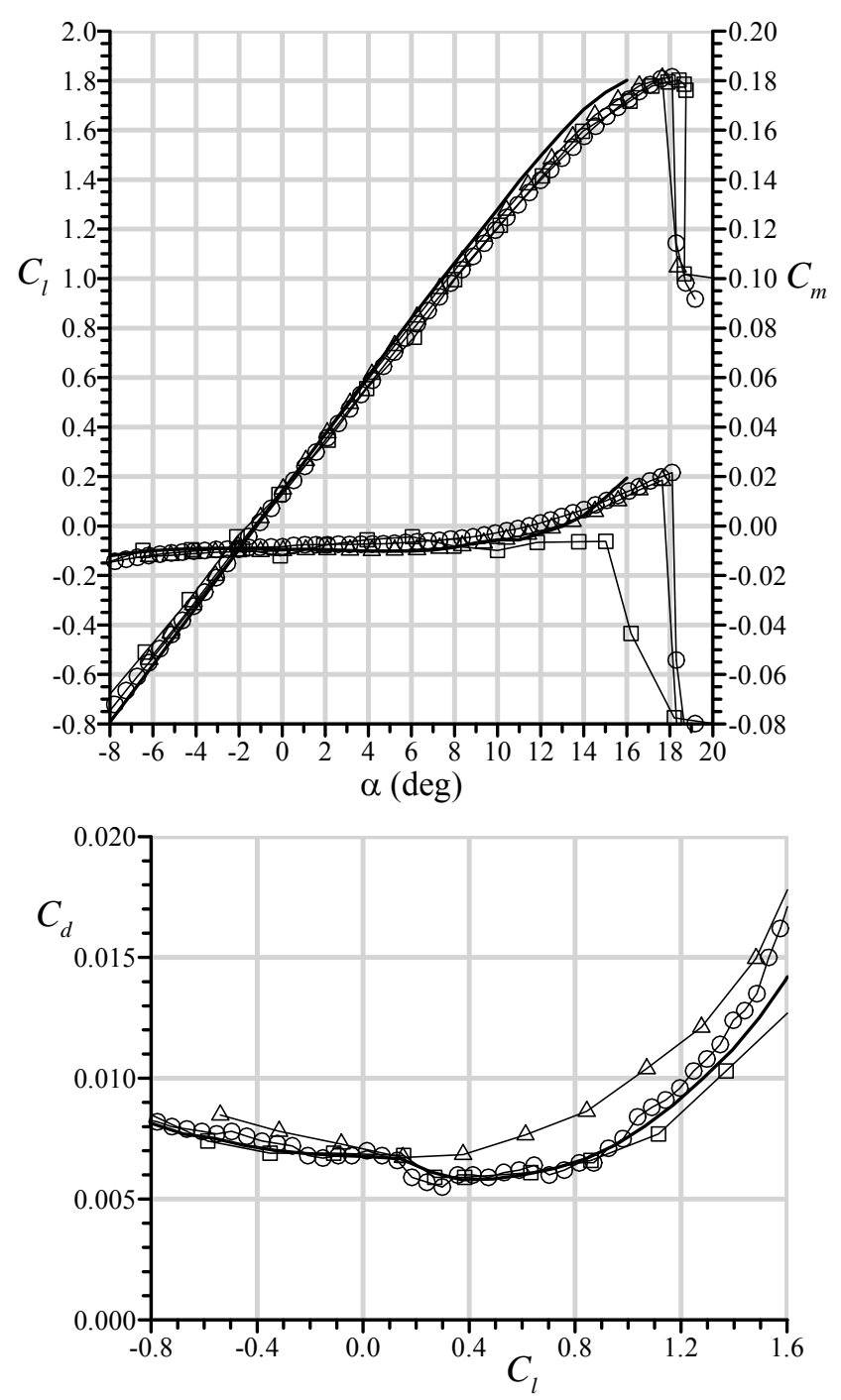

Figure 9.-Comparison of clean NACA 23012 airfoil section performance from the current work with results from Broeren et al. (Ref. 5), Abbott and von Doenhoff (Ref. 26) and XFOIL (Ref. 28) at closely matched Reynolds and Mach number. 
tolerances of the various models. The present data had $C_{l, \max }=1.82$ while the values for Broeren et al. (Ref. 5) and Abbott and von Doenhoff (Ref. 26) were 1.81 and 1.80, respectively. There was a slightly larger discrepancy in stalling angle of attack with $\alpha_{\text {stall }}=18.1^{\circ}$ for the present data and $17.6^{\circ}$ and $18.4^{\circ}$ for the other sources. Some of this disagreement could be due to the angle of attack resolution at which the data were acquired and flow angularity in the windtunnel. For example, the Broeren et al. (Ref. 5) data were only acquired in one degree increments, so it is quite possible that a higher stalling angle could have been measured with finer resolution in that test. The XFOIL results were computed for a Reynolds number of $9.0 \times 10^{6}$ and a Mach number of 0.20 . XFOIL is an airfoil analysis code that couples a panel method flowfield solver to an integral boundary-layer formulation (Ref. 28). The lift coefficient trends show that the XFOIL results compared favorably with all of the experimental data. The former had a slightly higher lift-curve slope which is a common characteristic of XFOIL results, in the authors' experience.

The agreement in the quarter-chord pitching moment variation with angle of attack was very good between the present data and the Broeren et al. (Ref. 5) data, with the latter being slightly more nose down for positive angles of attack. The agreement with the Abbott and von Doenhoff (Ref. 26) pitching-moment data is not as good owing to some noted deficiencies in their balance arrangement (Refs. 5 and 26). The XFOIL calculations also reproduce the appropriate $C_{m}$ versus $\alpha$ trend, matching up best with the Broeren et al. (Ref. 5) data. For drag coefficient, the agreement between the present data and Abbott and von Doenhoff (Ref. 26) is good, particularly for lift coefficients less than about 1.0. Both data sets have the characteristic reduction in $C_{d}$ at $C_{l} \approx 0.10$, also present in the XFOIL results. The large difference in the Broeren et al. (Ref. 5) $C_{d}$ data was shown to be related to the mismatch of spanwise running seams for the removable leading edge on that model (Ref. 29). While the present model also had a removable leading edge, the match of the spanwise running seams was excellent. The Abbott and von Doenhoff (Ref. 26) model was solid, i.e., no seams. The XFOIL results agreed fairly well with the present data and Abbott and von Doenhoff for most of the lift range until $C_{l} \approx 1.0$. These performance comparisons show that valid data were obtained for the clean NACA 23012 airfoil section in the current work.

The pressurization capability of the F1 facility allowed for the independent exploration of Reynolds and Mach number effects on the airfoil performance. The performance results for the NACA 23012 exhibited classic airfoil behavior. For example, the lift data show that $C_{l, \max }$ increased from 1.76 at $R e=4.6 \times 10^{6}$ to 1.84 at $R e=8.1 \times 10^{6}$ to 1.88 at $R e=12.3 \times 10^{6}$ with $M=0.10$. The stalling angle also increased over this range of Reynolds number and the pitching moment values near stall also became slightly more nose down. These Reynolds number trends agree with archival data for the NACA 23012 and data for other airfoils. The effect on maximum lift coefficient is summarized in Figure 10. Included
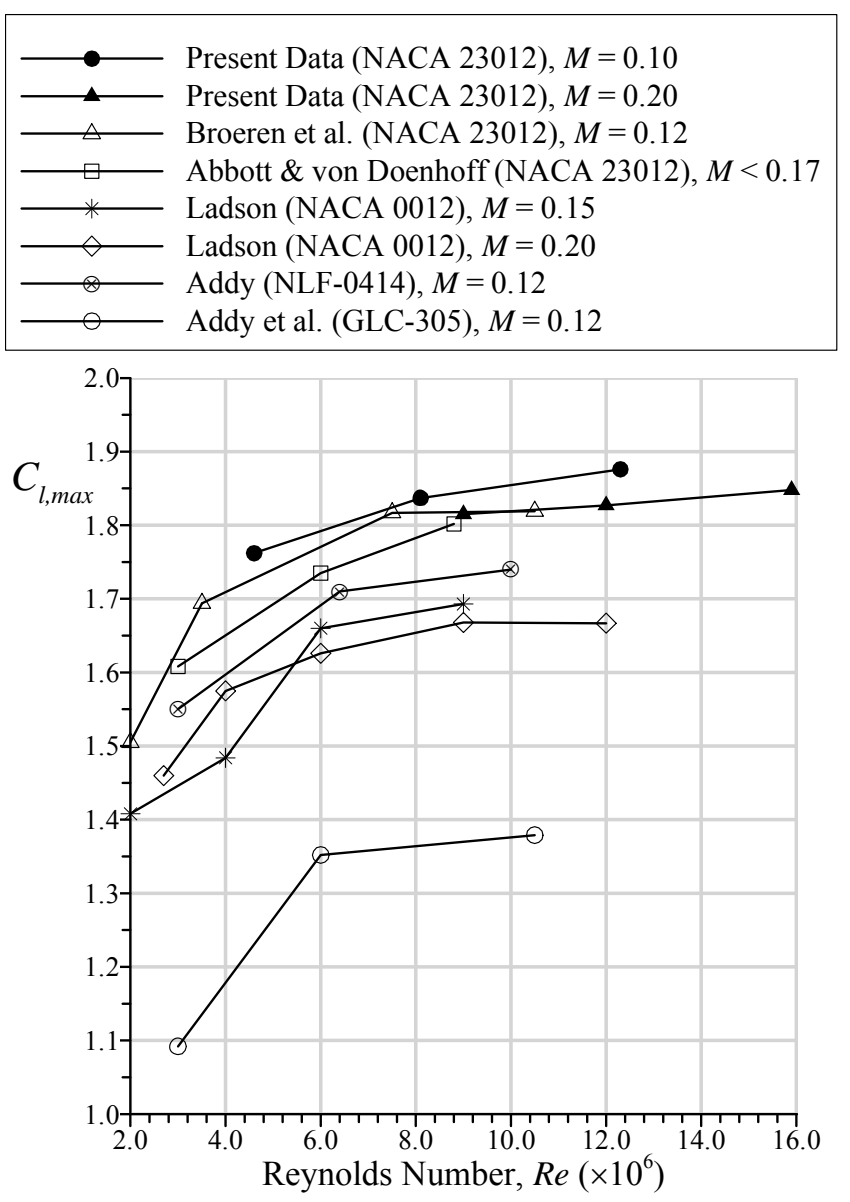

Figure 10.-Comparison of the effect of Reynolds number on maximum lift coefficient for the NACA 23012 airfoil from the current work with Broeren et al. (Ref. 5), Abbott and von Doenhoff (Ref. 26), NACA 0012 airfoil data from Ladson (Ref. 30), NLF 0414 airfoil data from Addy (Ref. 9) and GLC-305 airfoil data from Addy et al. (Ref. 6).

in Figure 10 are NACA 23012 section data from Broeren et al. (Ref. 5) Abbott and von Doenhoff (Ref. 26), NACA 0012 data reported by Ladson (Ref. 30), NLF-0414 data from Addy (Ref. 9), and GLC-305 data from Addy et al. (Ref. 6). The NACA 0012 data were acquired in the LTPT on a 24-in. chord model. The NLF-0414 and GLC-305 data were also acquired in the LTPT using 36-in. chord models. The GLC-305 section was fairly thin (less than 9 percent) and not highly cambered, thus resulting in the lower $C_{l, \max }$ values shown in Figure 10. These data indicate that large increases in $C_{l, \max }$ occur for Reynolds numbers less than about $6.0 \times 10^{6}$ and increasing Reynolds number above this results in only modest increases in $C_{l, \max }$. These results compare favorably with Haines's (Ref. 31) detailed review of scale and Reynolds number effects on airfoil stalling characteristics. There is good agreement in the $C_{l, \max }$ values for the three different sources of NACA 23012 section data in Figure 10, especially given the difference in models, model scales, facilities and installations. 

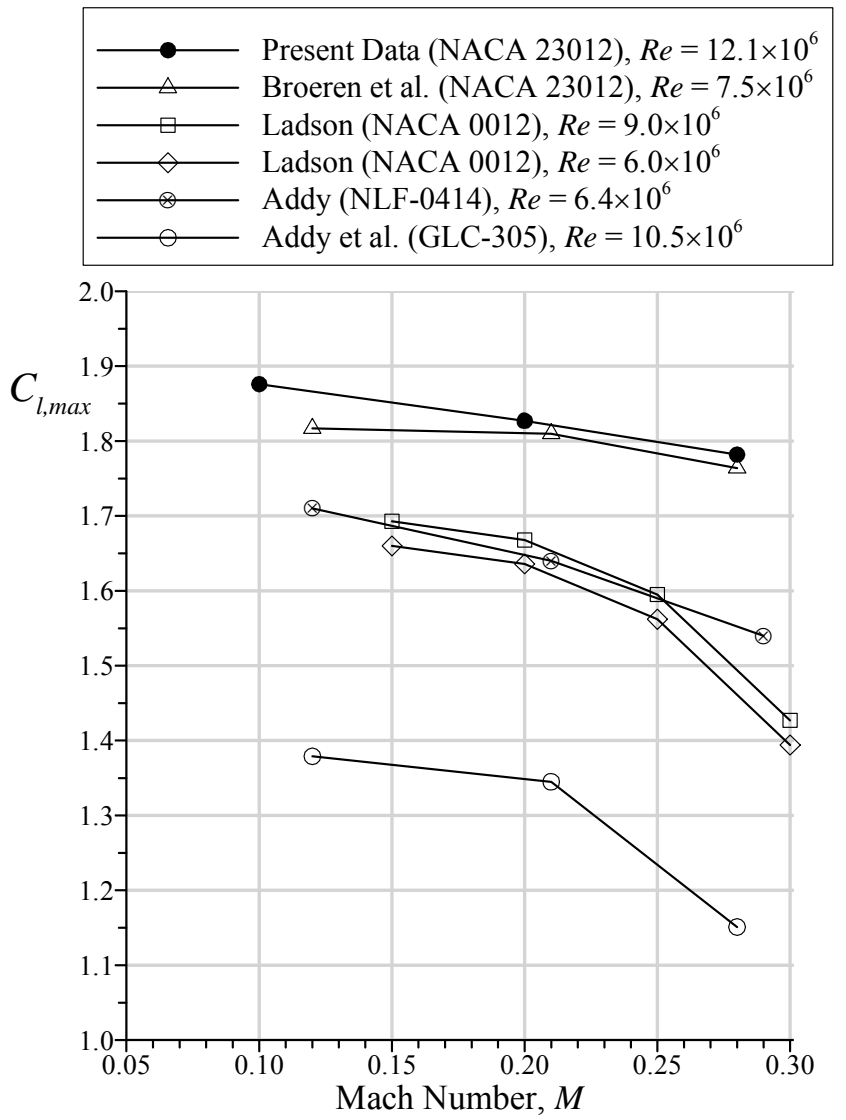

Figure 11.-Comparison of the effect of Mach number on maximum lift coefficient for the NACA 23012 airfoil from the current work with Broeren et al. (Ref. 5), NACA 0012 airfoil data from Ladson (Ref. 30), NLF-0414 airfoil data from Addy (Ref. 9) and GLC-305 airfoil data from Addy et al. (Ref. 6).

Some of the difference can also be attributed to differences in Mach number.

The effects of compressibility were documented for the clean NACA 23012 airfoil section by varying Mach number from 0.10 to 0.28 at a constant Reynolds number of $12.1 \times 10^{6}$. Once again, classic airfoil behavior was observed in the characteristic increases in the lift-curve slope and pitchingmoment slope just prior to stall for increasing Mach number. The maximum lift coefficient and stalling angle of attack both decreased with increasing Mach number, as expected. These results for $C_{l, \text { max }}$ are summarized in Figure 11 along with data from the other sources mentioned in connection with Figure 10. The data for the NACA 0012 and GLC-305 airfoils show more significant reduction in $C_{l, \max }$ for Mach numbers larger than 0.20, while the data for the NACA 23012 and NLF-0414 sections show mixed results. The sensitivity to Mach number is linked to local supersonic flow near the leading edge at high angles of attack, and so depends, in part, on the airfoil's leading-edge radius of curvature. The present data indicate a more linear decrease in $C_{l, \max }$ over the given Mach number range, while the trend in the Broeren et al. (Ref. 5) data aligns more closely with the other airfoils. Despite these minor differences, the overall Reynolds and Mach number effects and the comparison to historical data yield confidence in these measurements.

\subsection{Iced-Airfoil Aerodynamics}

The ice-casting simulations applied to the NACA 23012 airfoil caused a large range of detrimental performance effects due to the differences in the ice accretion geometries and roughness levels. The general range in performance degradation is illustrated in Figure 12 for four of the six artificial ice shapes at $R e=15.9 \times 10^{6}$ and $M=0.20$. The clean airfoil $C_{l, \max }$ value was 1.85 and $\alpha_{\text {stall }}$ was $18.1^{\circ}$ for this Reynolds and Mach number condition. The EG1162 streamwise and EG1126 roughness shapes had a very similar effect on lift, drag and pitching moment. The effect of the EG1162 ice simulation was to reduce $C_{l, \max }$ to 1.16 and $\alpha_{\text {stall }}$ to $11.9^{\circ}$. The EG1126 roughness shape caused a slightly larger lift penalty, yielding $C_{l, \max }=1.09$ at $\alpha_{\text {stall }}=11.4^{\circ}$. Both of these ice simulations caused a significant redistribution of surface pressure resulting in an increase in the pitchingmoment slope. The stall characteristics and surface pressure distribution indicate that there was likely some boundary-layer separation on the aft portions of the airfoil. The sharp drop in $C_{l}$ near $C_{l, \max }$ is reminiscent of the clean leading-edge stall type. The plot of drag coefficient shows that the EG1162 and EG1126 shapes also had a similar effect, with the former having a slightly higher $C_{d}$ up to $\alpha \approx 8.5^{\circ}$, where there was a crossover. At higher angles of attack the EG1162 streamwise ice shape caused a lower $C_{d}$, as compared to the EG1126 shape, which is consistent with the higher lift coefficients.

The performance results with the streamwise (EG1162) and roughness (EG1126) shapes sharply contrast the effect of the horn (EG1164) and spanwise-ridge (EG1159) shapes. The size and location of the latter two ice shapes on the airfoil caused large upper-surface separation bubbles that significantly altered the flowfield and the subsequent performance. The resulting maximum lift coefficient for the EG1164 horn shape was 0.86 at $\alpha_{\text {stall }}=8.8^{\circ}$ which amounted to a 54 percent reduction in $C_{l, \text { max }}$ from the clean airfoil at this Reynolds and Mach number condition. The effect of the EG1159 spanwise-ridge shape was even more severe with $C_{l, \max }=0.52$ at $\alpha_{\text {stall }}=5.6^{\circ}$. The lift and pitching moment data for the airfoil with these ice shapes are consistent with the understanding of the flowfield effects relating to the large separation bubble formed downstream of the horn and ridge (Refs. 13 and 14). As discussed at length by Bragg et al., (Refs. 13 and 14) the separation bubble is known to have large-scale unsteady characteristics. In the time-averaged sense, the separation bubble grows rapidly in chordwise extent with increasing angle of attack, until the unsteady reattachment region approaches the airfoil trailing-edge. The time-averaged bubble 

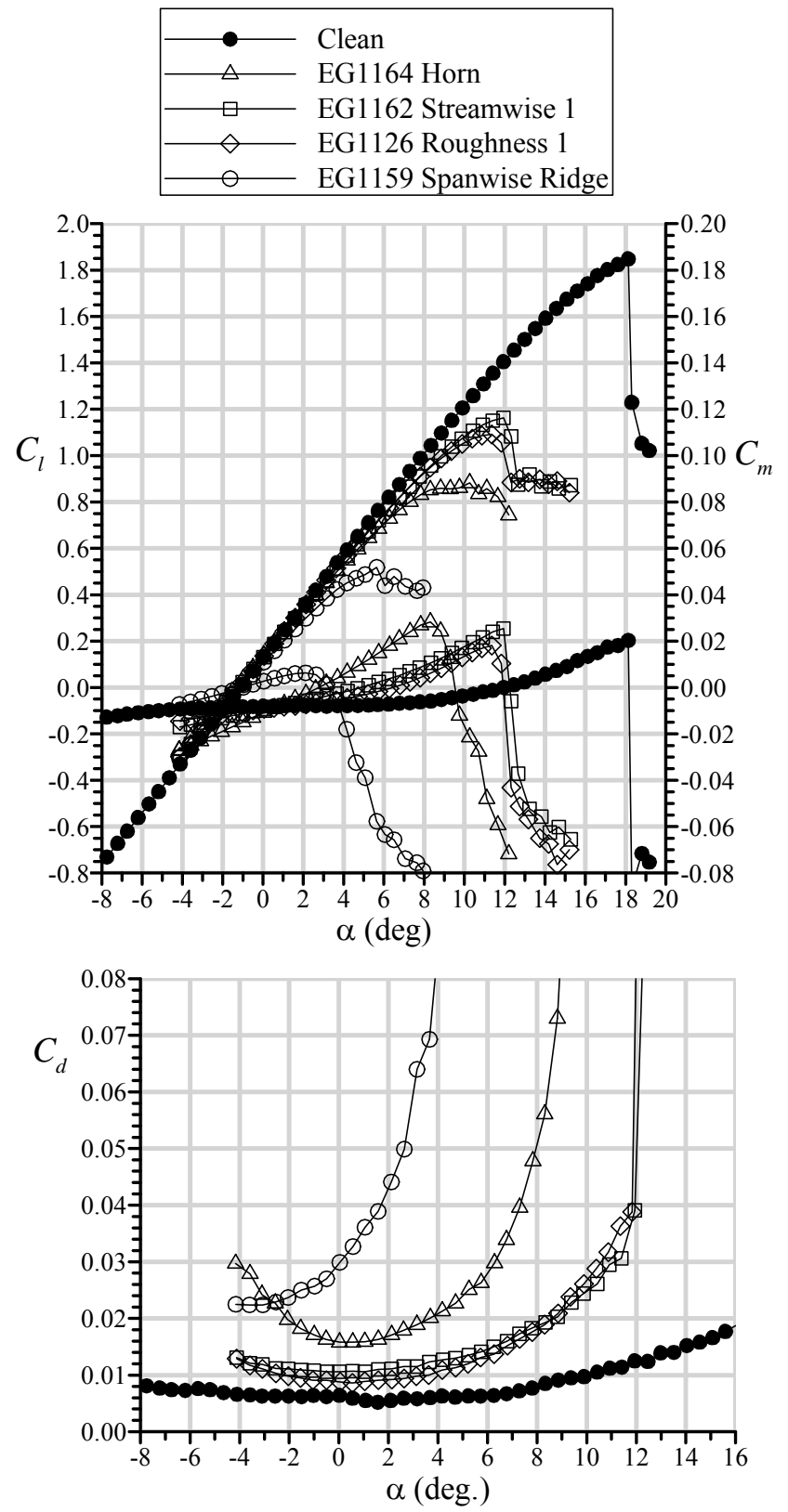

Figure 12.-Comparison of performance effects of the simulated ice configurations on the NACA 23012 airfoil at $\operatorname{Re}=15.9 \times 10^{6}$ and $M=0.20$.

growth is a feature of the classic thin-airfoil stall type described in detail by McCullough and Gault (Ref. 27). The plot of drag coefficient in Figure 12 further illustrates the significant impact of the separation bubble for the EG1164 and EG1159 ice-shape simulations. It is interesting to note that $C_{d}$ for the EG1159 spanwise ridge is lower than that for the EG1164 horn shape for angles of attack less than about $-2.5^{\circ}$. This most likely occurred because at low angle of attack drag coefficient is affected primarily by ice accretion on the airfoil lower surface. A comparison of Figures 2 and 5 clearly shows that the horn shape had larger height and extent of ice accretion on the lower surface, albeit closer to the leading edge. This effect of lower and upper-surface ice accretion on drag is described by Bragg et al. (Ref. 14) and in much more detail by Kim (Ref. 32). For angles of attack larger than $-2.5^{\circ}$, the drag coefficient for the spanwise-ridge shape was much larger, which was consistent with the lower $C_{l, \max }$. The fact that the spanwise-ridge ice simulation resulted in the largest performance degradation was likely due to the location of the upper-surface ridge. As depicted in Figures 2 and 5, the horn height was larger than the upper-surface ridge, but the ridge was located at $x / c \approx 0.06$. Lee and Bragg (Ref. 33) showed that for the NACA 23012 airfoil, the most sensitive location for ice accretion (of this size) in terms of loss in maximum lift was downstream of the leading edge. This is also illustrated in Figure 12 for the streamwise shape that formed on the airfoil leading edge, as the performance penalty was not nearly as severe as for the spanwise ridge.

The effect of leading-edge ice accretion on the NACA 23012 airfoil performance is further illustrated in Figure 13. These data are for the EG1125 and EG1134 streamwise and roughness ice shapes compared to the streamwise and roughness shapes plotted in Figure 12. Of these, it is interesting to note that the lowest iced-airfoil $C_{l, \max }$ occurred with the EG1126 roughness shape. The drag penalty was also largest for this shape for angles of attack greater than $9^{\circ}$. Note that there is a scale change between Figures 12 and 13 in the $C_{d}$ versus $\alpha$ plot to facilitate the comparisons. The fact that the two streamwise ice simulations (EG1162 and EG1125) had a nearly identical effect on $C_{l, \max }$ and $C_{d}$ (for $\alpha>9^{\circ}$ ) as the EG1126 roughness shape reveals an important characteristic about leading-edge ice accretion on the NACA 23012 section. A comparison of the ice accretion characteristics in Figures 3, 4 and 6 and icing environment in Table 2, shows a wide range of icing conditions and resulting sizes and shapes. The obvious implication is that the basic ice height or thickness for these types of accretions is not a strong driver of the stall performance behavior. A similar effect has been observed in previous testing of a subscale NACA 23012 airfoil with larger geometric quarter-round ice simulations located at the leading edge (i.e., $x / c=y / c=0$ ). Lee and Bragg (Ref. 33) showed that the iced airfoil $C_{l, \max }$ varied from about 1.01 to 0.97 as the ice height (or thickness) varied from $k / c=0.006$ to 0.014 . A similar $C_{l, \max }$ range was observed in Figure 13; 1.09 for the EG1126 simulation to 1.16 for the EG1162 simulation. Despite the similarity in $C_{l, \max }$ values, there is a difference in the stalling characteristics with the EG1162 and EG1126 simulations having a sharper, leading-edge type stall versus the EG1125 simulation that resulted in a more gradual trailingedge type stall. This implies that significant flowfield differences remain among the various artificial ice shapes despite the alignment of maximum lift coefficient. These effects are addressed further in Section 4.4.

The data for the EG1134 simulation illustrate the smallest maximum lift penalty measured for the given set of artificial ice shapes. The $C_{l, \max }$ of 1.28 was about 10 percent higher than for the other three ice simulations in Figure 13. The drag 

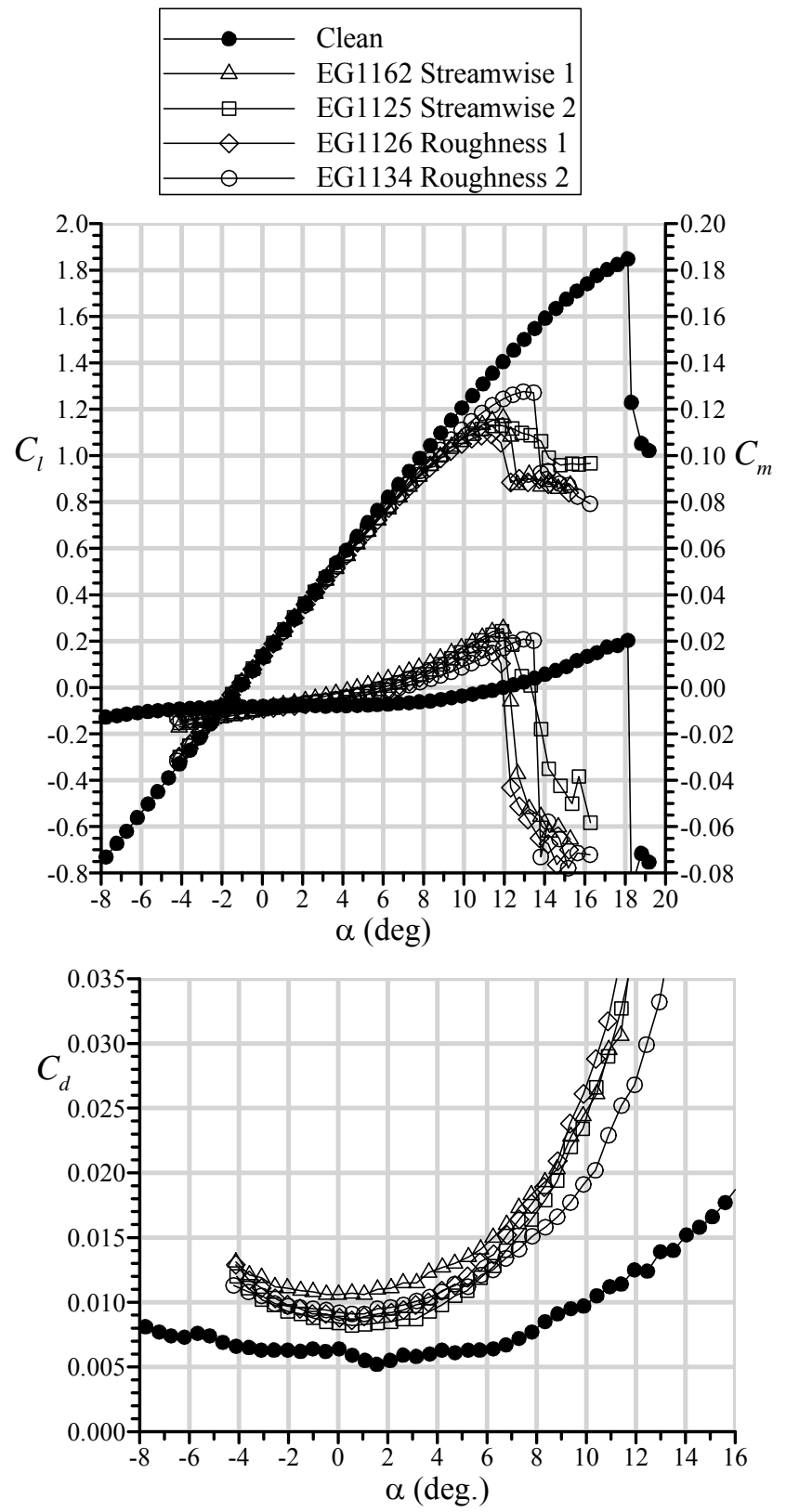

Figure 13.-Comparison of performance effects of the roughness and streamwise ice simulations on the NACA 23012 airfoil at $R e=15.9 \times 10^{6}$ and $M=0.20$.

coefficient on the interval $-1.5<\alpha<4.7^{\circ}$ was slightly higher than, but most similar to the drag coefficient for the other roughness simulation, EG1126. It is interesting that the lift performance of the NACA 23012 section with the EG1134 simulation was very similar to the 80-grit sandpaper $(k / c=0.00023)$ reported by Broeren et al. (Ref. 5) on the 36in. chord model of the same airfoil. For that case, the $C_{l, \max }$ was about 1.30 at $R e=7.5 \times 10^{6}$ and $M=0.21$. The minimum $C_{d}$ for the airfoil with the 80 -grit sandpaper was 0.010 , about 10 percent higher than for the EG1134 roughness simulation in the present data. The comparison of the EG1134 performance effects to the 80-grit sandpaper on the 36-in. chord model is useful because the latter is roughly equivalent to 40-grit sandpaper on a full-scale wing, which is often used in aircraft certification flight testing applications (Ref. 34).

The trends in the drag coefficient variation with angle of attack for the iced-airfoil configurations in Figure 13 may be interpreted in terms of the icing environment from which these simulations were obtained. In the case of the two streamwise ice simulations, for example, the drag coefficient for the EG1162 configuration was higher than for the EG1125 configuration in the range of $-4^{\circ}$ to $8^{\circ}$. This is somewhat surprising given that the former ice shape was more conformal to the airfoil leading edge than the latter. However, the former was accreted with a larger MVD drop size and therefore the downstream roughness covered a larger surface extent. This may be at least partially responsible for the larger drag over this range. It was noted above that the drag coefficient for the EG1134 roughness configuration was slightly higher than for the EG1126 roughness configuration over the interval $-1.5<$ $\alpha<4.7^{\circ}$. This may have occurred because the rime roughness EG1134 was accreted with a larger MVD drop size resulting in a larger surface extent of ice roughness. For angles of attack larger than $4.7^{\circ}$, it was likely that a larger extent of trailingedge separation developed for the EG1126 configuration, thus the drag coefficient grew larger than for the EG1134 configuration corresponding to the lower stalling angle.

\subsection{Iced-Airfoil Reynolds and Mach Number Effects}

The effect of Reynolds number variation at constant Mach number was explored for all of the ice-shape configurations. The pitch-polar data for the EG1125 streamwise-ice simulation are shown and discussed in Broeren et al. (Ref. 35). The lift and pitching moment data were virtually unchanged despite a nearly three-fold increase in Reynolds number from $4.6 \times 10^{6}$ to $12.0 \times 10^{6}$. There was a small increase in maximum lift coefficient from 1.10 at the lowest Reynolds number to 1.13 at the highest. The pitching moment data show that there was a small $0.5^{\circ}$ increase in the stall break as the Reynolds number was increased from $4.6 \times 10^{6}$ to $8.2 \times 10^{6}$. The drag data show slightly more dependence with the drag coefficient generally decreasing with increasing Reynolds number. The reason for this trend was not investigated in detail, but this effect on drag has been observed in other iced-airfoil studies (Ref. 5 and 6).

The Reynolds and Mach number effects data for the EG1125 configuration was representative of all of the ice simulations tested in this study. This was particularly true for the lift and pitching moment variations with Reynolds number, even for the small roughness shapes. Changes in Reynolds number over this range did not substantially change the character of the stall. That is, iced configurations with an abrupt, leading-edge stall character maintained this over the 


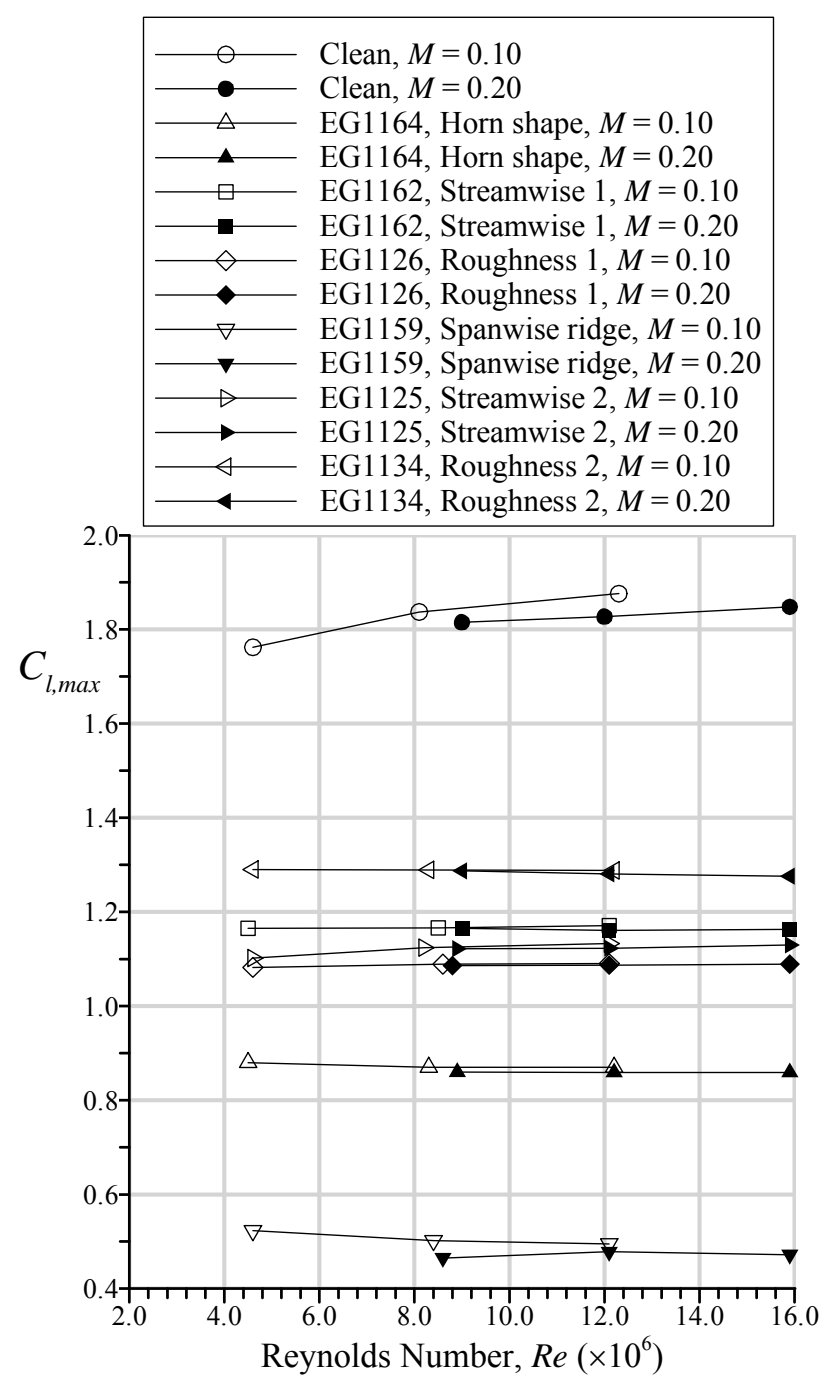

Figure 14.-Effect of Reynolds number on maximum lift coefficient for the clean NACA 23012 airfoil and with the simulated ice shapes.

test Reynolds number range. The effect on maximum lift coefficient for all of the simulations tested is summarized in Figure 14. Also included in the figure are the data for $M=0.20$. The non-effect of Reynolds number is consistent with the previous data compiled by Bragg et al. (Ref. 14). The authors argue that the presence of ice contamination on the airfoil governs the boundary-layer behavior such that the influence of Reynolds number on such processes is reduced to lower order effects unlike in the clean case. The present data continue to support this conclusion.

The data in Figure 14 were combined with data compiled from other sources in Figure 15. The purpose of this figure is to further illustrate the difference in clean versus iced-airfoil Reynolds number effects on maximum lift coefficient, which is an important aircraft safety-related parameter. Incorporated in Figure 15 are data for four different airfoils with numerous
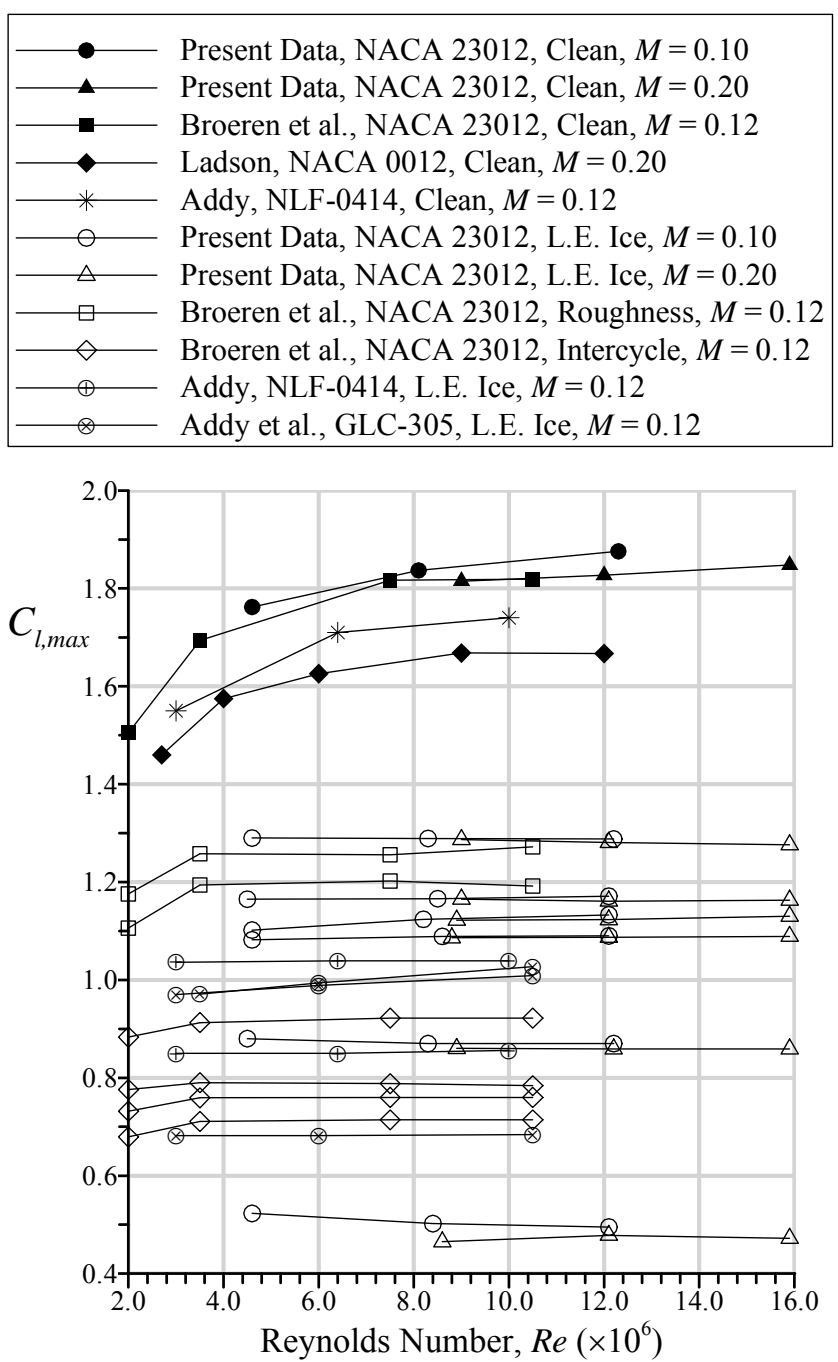

Figure 15.-Comparison of the effect of Reynolds number on maximum lift coefficient for the NACA 23012 airfoil from the current work with Broeren et al. (Ref. 5), NACA 0012 airfoil data from Ladson (Ref. 30), NLF 0414 airfoil data from Addy (Ref. 9) and GLC-305 airfoil data from Addy et al. (Ref. 6).

different kinds of simulated leading-edge ice accretion. These data show that for some iced-airfoil cases, most notably the sandpaper roughness due to Broeren et al. (Ref. 5), there can be measurable Reynolds number effects on $C_{l, \text { max }}$ for $R e<$ $4.0 \times 10^{6}$. The other data shown in Figure 15 that were taken from Broeren et al. (Ref. 5) are for "intercycle" ice shapes. These ice shapes, being larger, leading-edge type ice, did not result in significant $C_{l, \max }$ decreases for $R e<4.0 \times 10^{6}$. There is at least one other study (Ref. 36) (not plotted here) that further shows negligible variation in iced-airfoil $C_{l, \max }$ from $R e=2.0 \times 10^{6}$ to $10.5 \times 10^{6}$. Thus, increases in Reynolds number above $2.0 \times 10^{6}$ tend to have little or no effect on $C_{l, \max }$ for airfoils with large, leading-edge ice accretion. This is an important result for subscale simulation at low-Reynolds number. 


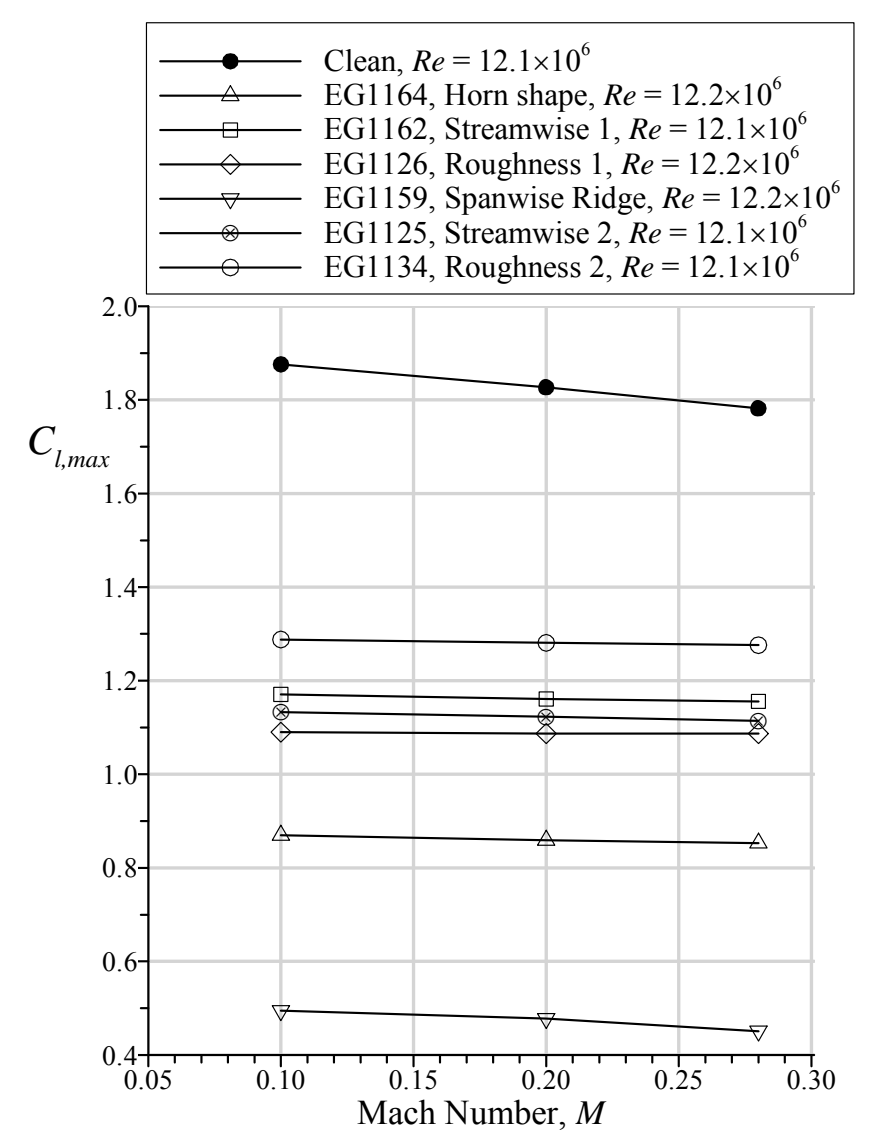

Figure 16.-Effect of Mach number on maximum lift coefficient for the clean NACA 23012 airfoil and with the simulated ice shapes.

Broeren et al. (Ref. 35) also show the effect of Mach number variation at constant Reynolds number in detail for the same EG1125 streamwise-ice simulation. The data show that the slopes of $C_{l}$ and $C_{m}$ with respect to angle of attack were increased prior to stall as the Mach number was increased from 0.10 to 0.28 . The maximum lift coefficient was reduced from 1.13 to 1.11 and stalling angle was reduced from $11.9^{\circ}$ to $10.9^{\circ}$ over this range. The minimum drag coefficient increased by a larger amount for Mach number increasing from 0.10 to 0.20 , with little change for Mach number increasing from 0.20 to 0.28 . In contrast, drag coefficients at higher angles of attack were influenced more strongly for increasing Mach number from 0.20 to 0.28 . Mach number performance sweeps for the other iced-airfoil configurations yielded similar results. The effect on maximum lift coefficient is summarized in Figure 16. The horn shape (EG1164) and the spanwise-ridge shape (EG1159) showed the most significant decrease in $C_{l, \max }$ over this range, with the smaller ice shapes showing much less dependence of $C_{l, \text { max }}$ on $M$. This trend involving smaller ice shapes and Mach number effects on $C_{l, \max }$ has been observed in other studies.

Plotted in Figure 17 are data compiled from a number of iced-airfoil studies. For example, Broeren et al. (Ref. 5) report data for two sandpaper roughness configurations and four
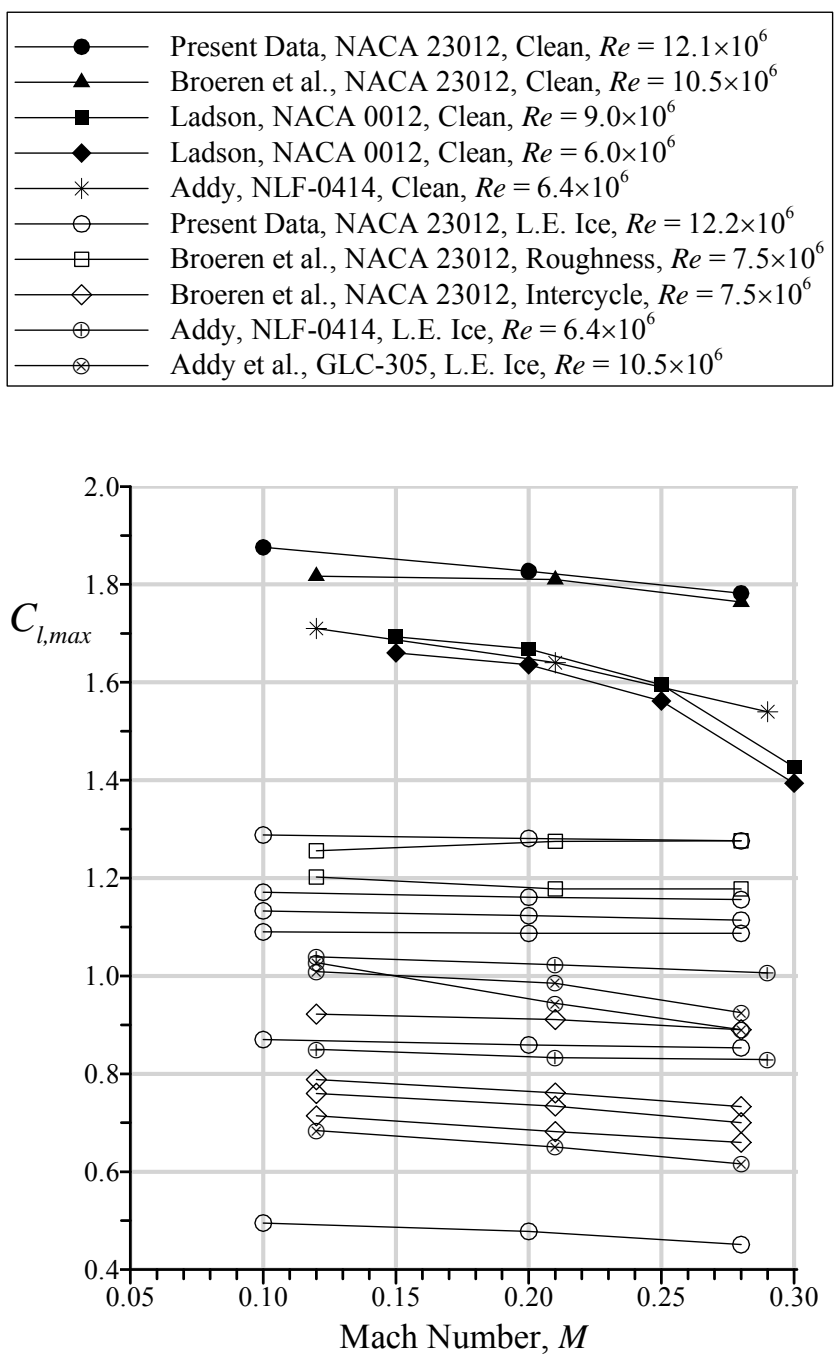

Figure 17.-Comparison of the effect of Mach number on maximum lift coefficient for the NACA 23012 airfoil from the current work with Broeren et al. (Ref. 5), NACA 0012 airfoil data from Ladson (Ref. 30), NLF-0414 airfoil data from Addy (Ref. 9) and GLC-305 airfoil data from Addy et al (Ref. 6).

intercycle ice configuration on the NACA 23012 section. For the two sandpaper roughnesses, there was a very slight decrease in $C_{l, \max }$ for one case and an increase in $C_{l, \max }$ for the other case over a Mach number range of 0.12 to 0.28 . In contrast, the much larger, ridge-type intercycle ice configurations resulted in $C_{l, \max }$ variations with Mach number similar to that shown in Figure 16 for the EG1164 and EG1159 simulations. The data for the leading-edge, icedairfoil configurations on the NLF-0414 and GLC-305 airfoils from Addy et al., (Refs. 6, 7 and 9) also exhibit similar Mach number trends. The decrease in $C_{l, \max }$ with increasing Mach number for larger ice shapes appears to be related to an increase in the size of the separated flow region and is described in more detail by Bragg et al. (Ref. 14) and Broeren et al. (Ref. 36). 


\subsection{Discussion of Iced-Airfoil Stalling Characteristics}

The stalling characteristics of the iced-airfoil configurations tested in this study are of key interest, not only as they relate to the safety of flight operations, but also as they relate to the subscale component of this work described by Bragg et al. (Ref. 12). The lack of significant Reynolds and Mach number effects on maximum lift coefficient implies that simulation of iced performance at small scale may be quite successful. In a given subscale simulation, it is also important that the stalling characteristics are maintained in addition to any one parameter such as $C_{l, \max }$ or $\alpha_{\text {stall }}$. The development of airfoil stall classifications relates back to early research of B. Melvill Jones (Ref. 38), among others. McCullough and Gault (Ref. 27) built upon the foundations of this early work and conducted a systematic series of airfoil section tests to establish the commonly accepted stall-type definitions in use today. Trailing-edge stall is preceded by movement of the turbulent boundary-layer separation point forward from the trailing edge with increasing angle of attack. Leading-edge stall has abrupt flow separation near the leading edge generally without subsequent reattachment. The "abrupt" separation usually results from the "bursting" of a small laminar separation bubble that results in a sharp decrease in lift. Thin-airfoil stall is preceded by flow separation at the leading edge with reattachment (laminar separation bubble) at a point that moves progressively downstream with increasing angle of attack. Stall type is a function of several variables such as Reynolds number, surface roughness or free-stream turbulence. Therefore, any particular airfoil may exhibit a combination of stall types, or its stall type may change over various flow regimes or conditions.

Over the range of Reynolds and Mach numbers in this study the clean NACA 23012 airfoil clearly exhibits the leadingedge stall type. The abrupt flow separation at stall was evident from the flow visualization and pressure distributions and is manifest in the sharp drop in lift coefficient. Both Haines (Ref. 31) and Tani (Ref. 39) conducted extensive reviews of airfoil stall research and noted that the abrupt flow separation associated with leading edge stall can result from either the bursting of a small laminar separation bubble (as reported by McCullough and Gault (Ref. 27)) or from re-separation of the turbulent boundary-layer downstream of the bubble reattachment location. Haines makes the case that the latter separation mechanism is probably more likely for moderate to high-Reynolds number flows. So the bursting of the laminar separation bubble is not a necessary prerequisite for leadingedge stall. In either case, there is no question about the basic stall type of the clean NACA 23012 section.

The application of the simulated ice shapes to the NACA 23012 airfoil section alters the stall type in some cases. It is clear that the main stall mechanism for the EG1164 horn shape and EG1159 spanwise-ridge shape configurations was the growth (with angle of attack) of a large upper-surface separation bubble. Thus, the airfoil with these ice shapes would be classified as having the thin-airfoil stall type. This conclusion is based on lift performance data in Figure 12 and corroborated by the corresponding pressure distributions and flow visualization (not shown). These flowfield physics are fairly well documented (e.g., see Bragg et al. (Ref. 13 and 14)). However, the stalling characteristics of the streamwise and roughness ice simulations on the NACA 23012 airfoil are not as well understood and deserve a closer look.

What is of primary interest here is that for three of the four roughness and streamwise ice simulations tested on the NACA 23012 airfoil, the presence of the simulated ice did not appear to significantly alter the leading-edge stall type. This observation is based upon the abrupt loss in lift at stall for the EG1162, EG1126 and EG1134 simulations (cf. Fig. 13). Only the EG1125 simulation resulted in a gradual loss of lift post stall. This comparison is illustrated in more detail in the pressure distributions where the EG1134 configuration is used as the example for leading-edge stall. The data plotted in Figure 18 for the iced-airfoil case at $\alpha=13.5^{\circ}$ and $13.8^{\circ}$ show the profound redistribution of surface pressure as the stall occurs with only a $0.3^{\circ}$ increase in angle of attack. The nearly constant pressure region aft of about $x / c=0.10$ results from the massive separation on the upper surface indicative of the leading-edge stall type. Also shown for comparison is the clean pressure distribution for $\alpha=13.5^{\circ}$ At this angle of attack the clean and iced pressures were very similar. There was some divergence of the pressure near the trailing edge in the latter case indicating that there was likely some extent of turbulent boundary-layer separation. This separation combined with the effects of the ice shape probably contributed to the reduced suction pressures on the forward portion of the airfoil relative to the clean configuration. Technically, the iced-airfoil stall type may be classified as a combination of leading-edge and trailing-edge stall due to the presence of the turbulent boundary-layer separation. However, the abrupt redistribution of surface pressure (at $\alpha=13.8^{\circ}$ ) is a clear hallmark of leading-edge stall.

This behavior is contrasted with the data in Figure 19 for the EG1125 streamwise-ice simulation. The iced-airfoil pressure distributions correspond to maximum lift $\left(\alpha=11.9^{\circ}\right)$ and $1.5^{\circ}$ post stall $\left(\alpha=13.3^{\circ}\right)$. In contrast to the EG1134 case, the pressure distributions are comparable corresponding to the gradual reduction in lift coefficient shown in Figure 13. There was more of a divergence of $C_{p}$ on the aft section of the airfoil at the higher angle of attack indicating a larger extent of turbulent boundary-layer separation. However, the salient feature for both angles of attack is the near-constant pressure region between $x / c=0.015$ and 0.05 . This probably indicates the presence of a separation bubble induced by the simulated ice shape. The bubble significantly altered the pressure distribution from the clean case, such that the tendency to leading-edge stall was altered. In fact, the EG1125 configuration could be classified as having trailing-edge stall, since the reduction in lift occurred due to the turbulent boundary-layer separation moving forward as angle of attack 


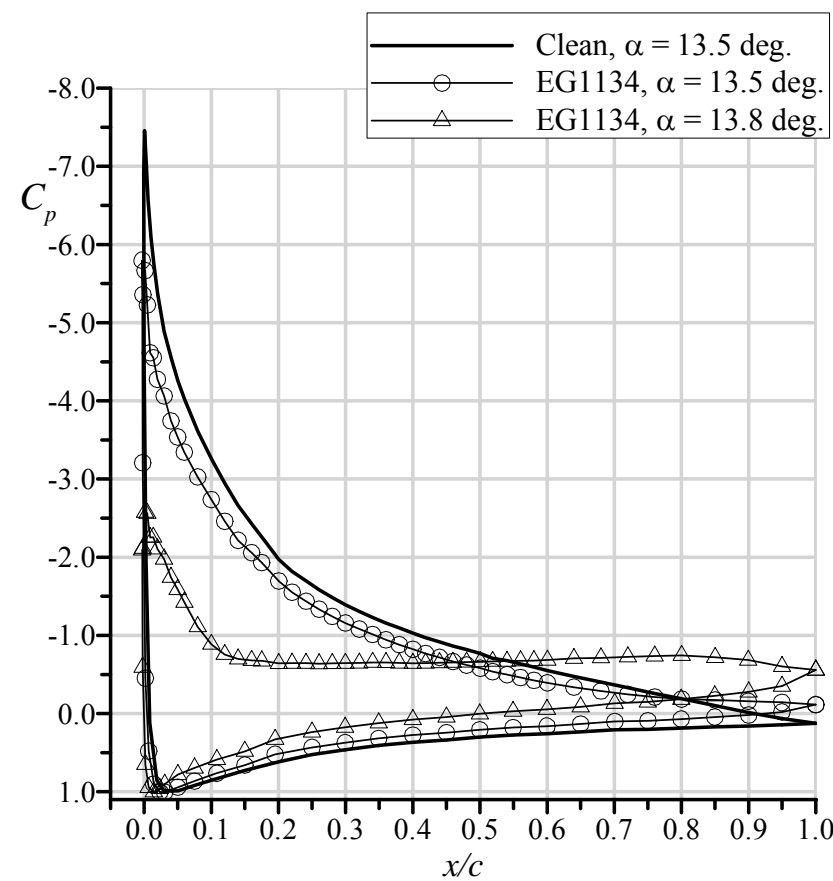

Figure 18.-Chordwise pressure distribution comparison for angles of attack near stall for the EG1134 roughness simulation on the NACA 23012 airfoil at $R e=15.9 \times 10^{6}$ and $M=0.20$.

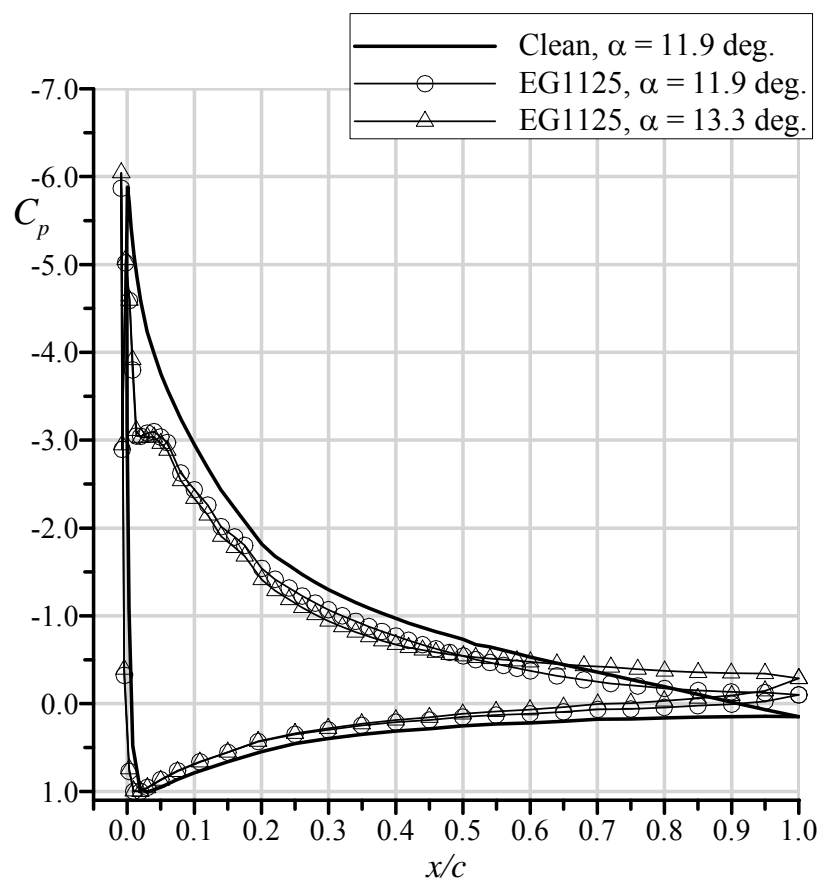

Figure 19.-Chordwise pressure distribution comparison for angles of attack near stall for the EG1125 streamwise shape on the NACA 23012 airfoil at $R e=15.9 \times 10^{6}$ and $M=0.20$. increased. While there was a small separation bubble present due to the ice shape, this bubble did not grow significantly in chordwise extent leading up to the stall. This partly explains the classification of this ice shape as streamwise ice, according to the descriptions established by Bragg et al. (Refs. 13 and 14). This behavior is contrasted with the EG1164 and EG1159 configurations that had the thin airfoil stall type. The stall mechanism for the EG1125 configuration is very different from the EG1164 and EG1159 configurations even though they shared a more gradual decrease in lift at stall. This is consistent with the characteristics of thin-airfoil and trailingedge stall as defined by McCullough and Gault (Ref. 27).

The fact that the leading-edge stall characteristics of the NACA 23012 airfoil were not significantly altered by the presence of two roughness and one streamwise-ice shapes is important for subscale simulations and computational modeling. As mentioned in this discussion, leading-edge stall is defined as abrupt flow separation near the leading edge of the airfoil without subsequent reattachment. With the ice simulations in question, there were likely small areas of boundary-layer separation present on the scale of the ice roughness. Research reported by Kerho and Bragg (Ref. 40) showed that leading-edge roughness can lead to a "transitional" boundary layer instead of acting as a "trip" with energetic transition to turbulence. The transition process due to ice-type roughness develops over a large part of the airfoil chord, up to 30 to 50 percent in some cases. The present data indicate that the "transitional" nature of the boundary layer is still susceptible to abrupt separation for the three ice simulations. In contrast, the other ice shapes being larger, caused larger-scale separation and alteration of the transition process as well as the pressure distribution, thus leading to an alteration of the stall type.

Another important feature of the roughness and streamwise ice shapes was that the effect on maximum lift was similar in magnitude despite the large variation in geometry. As discussed in connection with Figure 13, the range in $C_{l, \max }$ was from 1.09 to 1.28 . While this variation is not insignificant, it is small compared to the decrease from the clean value of 1.85 . These data were compared to other results for simulated leading-edge ice contamination on the NACA 23012 airfoil shown in Figure 20. There appears to be some dependence of $C_{l, \max }$ on ice (roughness) size located at the leading edge up to $k / c \approx 0.0015$. For sizes larger than this, there is no clear trend among the data gathered from various sources. The selected data are for a large range of ice-shape geometries and simulation methods. The roughness cases covered the leading edge, extending downstream several percent chord. The quarter-round data were simple geometric shapes with the forward face located at the leading edge. The intercycle 322 shape had characteristics similar to the EG1162 ice shape in the current study. The reduced sensitivity to these leadingedge ice simulations may be due in part to the favorable pressure gradient in this region. Since there is no clear correlation to the height of the simulated ice, the geometry, 


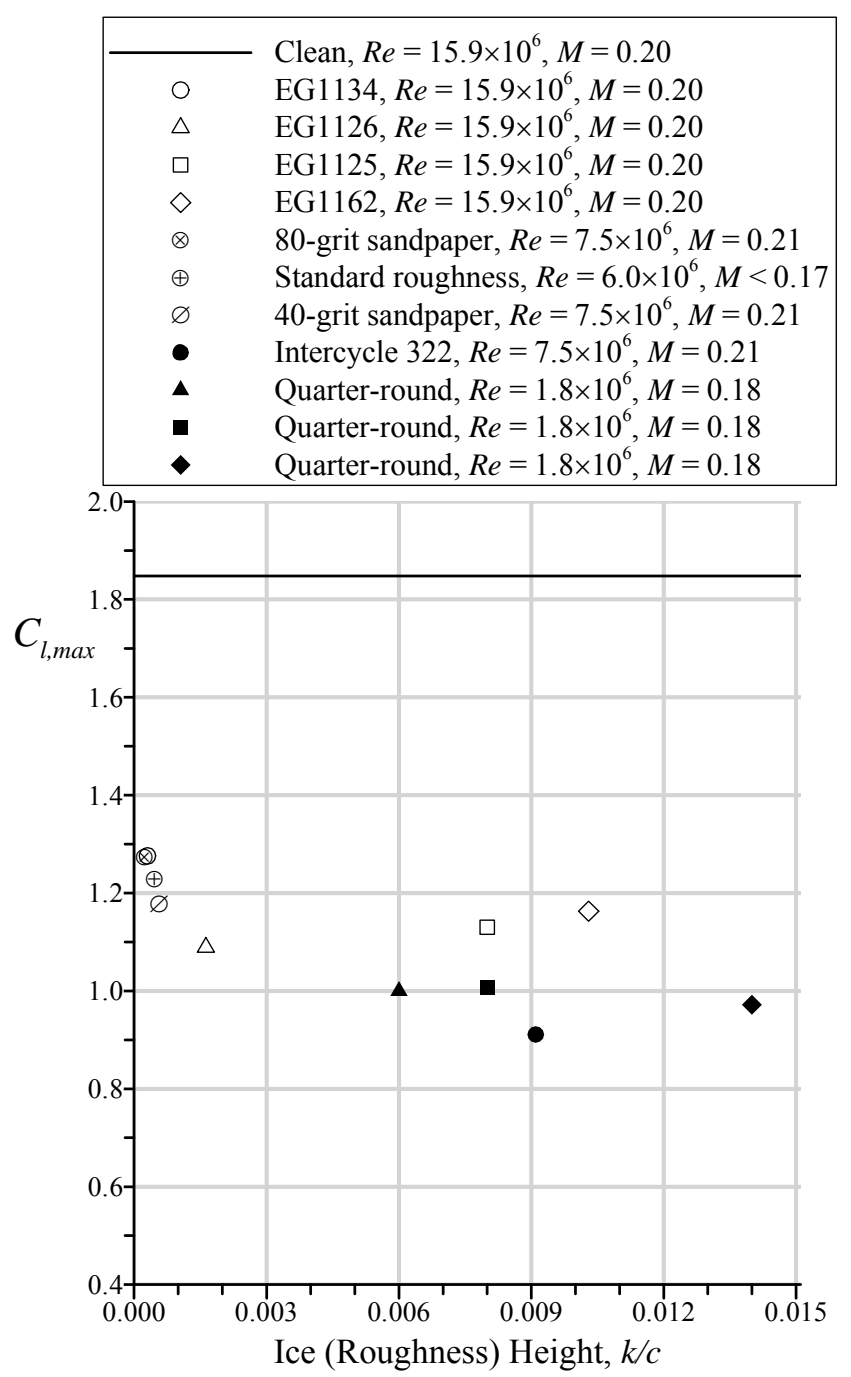

Figure 20.-Comparison of $C_{l, \max }$ dependence on ice (roughness) height for various simulations all applied to the leading-edge region of the NACA 23012 airfoil. In addition to the present data, the 80- and 40-grit sandpaper and intercycle 322 simulations are from Broeren et al. (Ref. 5). The NACA standard roughness datum is from Abbott \& von Doenhoff (Ref. 26). The quarter-round data are from Lee and Bragg (Ref. 33).

surface extent and distribution of the roughness play an important role in determining maximum lift. This type of result, while perhaps obvious in light of the present data, supports the notions of Bragg et al. (Refs. 13 and 14) in their development of the ice-shape classifications. This leads to an ironic conclusion for subscale simulation. The reduced sensitivity may allow for lower-fidelity simulations to yield acceptable values of maximum lift coefficient. The disadvantage is that the physics of the flowfield may not be properly modeled in the subscale case. Therefore, it may actually be more difficult to develop proper subscale simulations due to the reduced performance sensitivity of the roughness and streamwise ice shapes.

\subsection{Conclusions}

The purpose of this article is to report the results of a study establishing a high-fidelity, full-scale, iced-airfoil aerodynamic performance database. This research was conducted as a part of a larger program with the goal of developing subscale simulation methods for ice accretion. Airfoil performance testing was carried out at the ONERA F1 pressurized wind tunnel using a 72 -in. (1828.8-mm) chord NACA 23012 airfoil over a Reynolds number range of $4.5 \times 10^{6}$ to $16.0 \times 10^{6}$ and a Mach number range of 0.10 to 0.28 . A total of six ice-shape simulations were tested: one horn shape, one spanwise-ridge shape, two streamwise shapes and two roughness shapes. These artificial ice shapes were highfidelity castings made from molds obtained during earlier ice accretion testing at the NASA Glenn Icing Research Tunnel.

The artificial ice shapes had a large detrimental effect on the performance of the NACA 23012 airfoil. The spanwiseridge shape caused the largest reduction in maximum lift with a value of 0.52 compared to the clean value of 1.85 at $R e=$ $15.9 \times 10^{6}$ and $M=0.20$. The stalling angle was also reduced from $18.1^{\circ}$ down to $5.6^{\circ}$. There was a correspondingly large increase in the angle of attack dependence of the pitchingmoment coefficient. The minimum drag coefficient was increased by more than a factor of four from 0.0052 to 0.0224 . The performance of the airfoil with the horn shape was better than with the spanwise ridge, but still severely compromised from the clean configuration. For the same Reynolds and Mach numbers, the maximum lift coefficient was 0.86 at $8.8^{\circ}$ angle of attack. The minimum drag was increased by a factor of three from the clean value. The two roughness and streamwise-ice simulations had a similar range of performance effects on the airfoil. The range of maximum lift coefficient was 1.09 to 1.28 and the range of minimum drag coefficient was 0.0082 to 0.0106 at $R e=15.9 \times 10^{6}$ and $M=0.20$. The range of performance effects was small relative to the large differences in the size and geometry of the roughness and streamwise-ice shapes tested.

While the ice simulations negatively affected the stall performance of the NACA 23012 airfoil, half of the configurations tested resulted in a combination leading-edge and trailing-edge stall type. The abrupt loss of lift at stall associated with the leading-edge stall persisted for both the roughness and one streamwise-ice configurations, despite significant trailing-edge separation. This is an important detail for accurate subscale simulation because it means that while the ice shape was large enough to have a significant detrimental effect on the performance, the boundary layer in the leading-edge region was not significantly altered so as to prevent separation at the leading edge without subsequent reattachment. This also has important implications for the development of flight simulation models for iced-aircraft 
upsets. Proper modeling of iced-aircraft stall dynamics is important for pilot training in recovery techniques using a flight simulator. For the remaining streamwise-ice simulation the stall type was changed to a trailing-edge stall with gradual lift loss at stall. For the horn and spanwise-ridge shapes the stall was characteristic of thin-airfoil stall since there was a large upper-surface separation bubble that grew with increasing angle of attack precipitating the stall at such low values of lift coefficient and incidence.

The pressurization capability of the ONERA F1 Facility was used to document the effects of Reynolds and Mach number on the clean and iced performance. The clean airfoil maximum lift coefficient increased from 1.76 to 1.88 as the Reynolds number was increased from $4.6 \times 10^{6}$ to $12.3 \times 10^{6}$ at constant $M=0.10$. Increasing Mach number from 0.10 to 0.28 at a constant $R e=12.1 \times 10^{6}$ had the effect of reducing the maximum lift coefficient from 1.88 to 1.78 . The trends in lift and moment slope versus angle of attack and drag coefficient were consistent with classic airfoil behavior. For the airfoil with the ice simulations, there was virtually no measurable change in maximum lift coefficient over the entire Reynolds number range tested. Changes in Mach number had minor effects on maximum lift for the horn and spanwise-ridge shapes, but virtually no effects for the others. This lack of significant Reynolds and Mach number effects implies that subscale simulation of the iced-airfoil performance may be quite successful, despite the challenges associated with the roughness and streamwise-ice configurations' stalling mechanism.

\section{References}

1. Ratvasky, T.P., Van Zante, J.F., and Riley, J.T., "NASA/FAA Tailplane Icing Program Overview," AIAA Paper 99-0370, Jan. 1999.

2. Ratvasky, T.P., and Van Zante, J.F., "In-Flight Aerodynamic Measurements of an Iced Horizontal Tailplane," AIAA Paper 99-0638, Jan. 1999.

3. Ranaudo, R.J., Mikkelsen, K.L., McKnight, R.C., Ide, R.F., and Reehorst, A.L., "The Measurement of Aircraft Performance and Stability and Control After Flight Through Natural Icing Conditions," AIAA Paper 86-9758, Apr. 1986.

4. Reehorst, A.L., and Richter, G.P., "New Methods and Materials for Molding and Casting Ice Formations," NASA TM-100126, Sept. 1987.

5. Broeren, A.P., Bragg, M.B., and Addy, H.E., Jr., "Effect of Intercycle Ice Accretions on Aerodynamic Performance," Journal of Aircraft, Vol. 41, No. 1, Jan.-Feb. 2004, pp 165-174.

6. Addy, H.E., Jr., Broeren, A.P., Zoeckler, J.G., and Lee, S., "A Wind Tunnel Study of Icing Effects on a Business Jet Airfoil," AIAA Paper 2003-0727, Jan. 2003, also NASA/TM-2003212124, Feb. 2003.

7. Addy, H.E., Jr., and Chung, J.J., "A Wind Tunnel Study of Icing Effects on a Natural Laminar Flow Airfoil," AIAA Paper 2000 0095, Jan. 2000, also NASA/TM-2000-209775, Jan. 2000.

8. Papdakis, M., Yeong, H.W., Chandrasekharan, R., Hinson, M., Ratvasky, T., and Giriunas, J., "Experimental Investigations of
Simulated Ice Accretions on a Full-Scale T-tail," AIAA Paper 2001-0090, Jan. 2001.

9. Addy, H.E., Jr., "Ice Accretions and Icing Effects for Modern Airfoils," NASA/TP_-2000-210031, also DOT/FAA/AR-99/89, April 2000.

10. Anderson, D.N., "Manual of Scaling Methods," NASA/CR2004-212875, Mar. 2004.

11. Lynch, F.T., and Khodadoust, A., "Effects of Ice Accretion on Aircraft Aerodynamics," Progress in Aerospace Sciences, Vol. 37, No. 8, Nov. 2001, pp. 669-767.

12. Bragg, M.B., Broeren, A.P., Addy, H.E., Jr., Potapczuk, M., Guffond, D., and Montreuil, E., "Airfoil Ice-Accretion Aerodynamics Simulation," AIAA Paper 2007-0085, Jan. 2007.

13. Bragg, M.B., Broeren, A.P., and Blumenthal, L.A., "Iced-Airfoil and Wing Aerodynamics," SAE Paper 2003-01-2098, Jun. 2003.

14. Bragg, M.B., Broeren, A.P., and Blumenthal, L.A., "Iced-Airfoil Aerodynamics," Progress in Aerospace Sciences, Vol. 41, No. 5, Jul. 2005, pp. 323-418.

15. Blumenthal, L.A., "Surface Pressure Measurements on a ThreeDimensional Ice Shape," M.S. Thesis, Dept. of Aerospace Eng., Univ. of Illinois, Urbana, IL, 2005.

16. Blumenthal, L.A., Busch, G.T., Broeren, A.P., and Bragg, M.B., "Issues in Ice Accretion Aerodynamic Simulation on a Subscale Model," AIAA Paper 2006-0262, Jan. 2006.

17. Busch, G.T., "Ice Accretion Aerodynamic Simulation on a Subscale Model,” M.S. Thesis, Dept. of Aerospace Eng., Univ. of Illinois, Urbana, IL, 2006.

18. Busch, G.T., Broeren, A.P., and Bragg, M.B., "Aerodynamic Simulations of a Horn-Ice Accretion on a Subscale Model," AIAA Paper 2007-0087, Jan. 2007.

19. Broeren, A.P., Busch, G.T., and Bragg, M.B., "Aerodynamic Fidelity of Ice Accretion Simulation on a Subscale Model," SAE Paper 2007-01-3285, Sept. 2007. Also published in SAE 2007 Transactions Journal of Aerospace, Vol. 116, Sec. 1, Aug. 2008, pp. 560-575.

20. Busch, G.T., Broeren, A.P., and Bragg, M.B., "Aerodynamic Simulations of a Horn-Ice Accretion on a Subscale Model," Journal of Aircraft, Vol. 45, No. 2, Mar.-Apr. 2008, pp. 604613.

21. Busch, G.T., Broeren, A.P., and Bragg, M.B., "Aerodynamic Fidelity of Subscale, Two-Dimensional, Ice Accretion Simulations," AIAA Paper 2008-7062, Aug. 2008.

22. Desplas, P., "F1 Pressurized Subsonic Wind Tunnel User's Guide," Large Technical Facilities, Le-Fauga-Mauzac Wind Tunnels Department, ONERA, France, Nov. 1998.

23. Allen, H.J., and Vincenti, W.G., "Wall Interference in a TwoDimensional-Flow Wind Tunnel, with Consideration of the Effect of Compressibility," NACA Report 782, 1944.

24. Kline, S., and McClintock, F.A, "Describing Uncertainties in Single Sample Experiments," Mechanical Engineering, Vol. 75, No. 1, 1953, pp. 3-8.

25. Coleman, H.W., and Steele, W.G., Experimentation and Uncertainty Analysis for Engineers, Wiley-Interscience, New York, 1989, pp.40-118.

26. Abbott, I.H., and von Doenhoff, A.E., Theory of Wing Sections, Dover Publications, pp. 124-128 and 498-499, 1959.

27. McCullough, G.B., and Gault, D.E., "Examples of Three Representative Types of Airfoil-Section Stall at Low-Speed," NACA TN-2502, Sept. 1951. 
28. Drela, M., and Youngren, H. "XFOIL 6.96 User Guide," Aeronautical and Astronautical Engineering, Massachusetts Inst. of Technology, Cambridge, MA, 10 March 2001.

29. Broeren, A.P., and Bragg, M.B., "Effect of Residual and Intercycle Ice Accretions on Airfoil Performance," Dept. of Transportation, Federal Aviation Administration Rept. DOT/FAA/AR-02/68, May 2002.

30. Ladson, C.L., "Effects of Independent Variation of Mach and Reynolds Numbers on the Low-Speed Aerodynamic Characteristics of the NACA 0012 Airfoil Section," NASA TM4071, Oct. 1988.

31. Haines, A.B., "Scale Effects on Aircraft and Weapon Aerodynamics," AGARDograph, AGARD-AG-323, July 1994.

32. Kim, H.S., "Effect of Leading-Edge Ice Accretion Geometry on Airfoil Performance," M.S, Thesis, Dept. of Aeronautical and Astronautical Eng., Univ. of Illinois, Urbana, Illinois, 2004.

33. Lee, S., and Bragg, M.B., "Investigation of Factors Affecting Iced-Airfoil Aerodynamics," Journal of Aircraft, Vol. 40, No. 3, May-June 2003, pp. 499-508.

34. Cabler, S.J.M., "Aircraft Ice Protection," Federal Aviation Administration Advisory Circular, AC No. 20-73A, Aug. 16, 2006.
35. Broeren, A.P., Bragg, M.B., Addy, H.E., Jr., Lee, S., Moens, F., and Guffond, D., "Effect of High-Fidelity Ice Accretion Simulation on the Performance of a Full-Scale Airfoil Model," AIAA Paper 2008-0434, Jan. 2008.

36. Broeren, A.P., Lee, S., LaMarre, C.M., and Bragg, M.B., "Effect of Airfoil Geometry on Performance with Simulated Ice Accretions, Vol. 1: Experimental Investigations," Federal Aviation Administration, Washington, D.C., Office of Aviation Research, DOT/FAA/AR-03/64,” Aug. 2003.

37. Broeren, A.P., Bragg, M.B., and Addy, H.E., Jr., "Flowfield Measurements About an Airfoil with Leading-Edge Ice Shapes," Journal of Aircraft, Vol. 43, No. 4, July-Aug., 2006, pp. 12261234.

38. Jones, B.M., "An Experimental Study of the Stalling of Wings," Aeronautical Research Committee Reports and Memoranda, No. 1588, Dec. 1933.

39. Tani, I., "Low-Speed Flows Involving Separation Bubbles," Progress in Aeronautical Sciences, Vol. 5, No. 2, 1964, pp. 70-103.

40. Kerho, M.F., and Bragg, M.B., “Airfoil Boundary-Layer Development and Transition with Large Leading-Edge Roughness," AIAA Journal, Vol. 35, No. 1, Jan. 1997, pp. 75-84. 


\begin{tabular}{|c|c|c|}
\hline \multicolumn{2}{|c|}{ REPORT DOCUMENTATION PAGE } & $\begin{array}{l}\text { Form Approved } \\
\text { OMB No. 0704-0188 }\end{array}$ \\
\hline \multicolumn{3}{|c|}{ 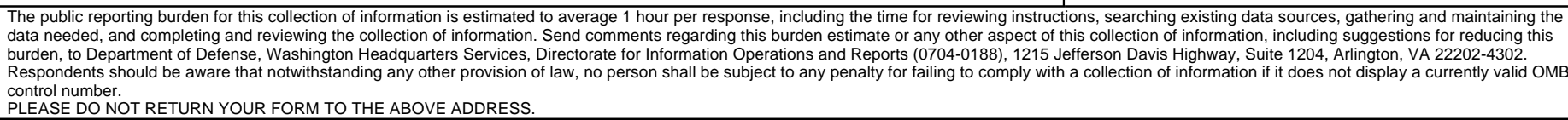 } \\
\hline $\begin{array}{l}\text { 1. REPORT DATE (DD-MM-YYYY) } \\
01-06-2010\end{array}$ & $\begin{array}{l}\text { 2. REPORT TYPE } \\
\text { Technical Memorandum }\end{array}$ & 3. DATES COVERED (From - To) \\
\hline \multirow{3}{*}{\multicolumn{2}{|c|}{$\begin{array}{l}\text { 4. TITLE AND SUBTITLE } \\
\text { Effect of High-Fidelity Ice Accretion Simulations on the Performance of a Full-Scale Airfo } \\
\text { Model }\end{array}$}} & 5a. CONTRACT NUMBER \\
\hline & & 5b. GRANT NUMBER \\
\hline & & 5c. PROGRAM ELEMENT NUMBER \\
\hline \multirow{3}{*}{\multicolumn{2}{|c|}{$\begin{array}{l}\text { 6. AUTHOR(S) } \\
\text { Broeren, Andy, P.; Bragg, Michael, B.; Addy, Harold, E., Jr.; Lee, Sam; Moens, Frederic; } \\
\text { Guffond, Didier }\end{array}$}} & 5d. PROJECT NUMBER \\
\hline & & 5e. TASK NUMBER \\
\hline & & $\begin{array}{l}\text { 5f. WORK UNIT NUMBER } \\
\text { WBS 457280.02.07.03.02.02 }\end{array}$ \\
\hline \multicolumn{2}{|c|}{$\begin{array}{l}\text { 7. PERFORMING ORGANIZATION NAME(S) AND ADDRESS(ES) } \\
\text { National Aeronautics and Space Administration } \\
\text { John H. Glenn Research Center at Lewis Field } \\
\text { Cleveland, Ohio 44135-3191 }\end{array}$} & $\begin{array}{l}\text { 8. PERFORMING ORGANIZATION } \\
\text { REPORT NUMBER } \\
\text { E-17281 }\end{array}$ \\
\hline \multirow{2}{*}{\multicolumn{2}{|c|}{$\begin{array}{l}\text { 9. SPONSORING/MONITORING AGENCY NAME(S) AND ADDRESS(ES) } \\
\text { National Aeronautics and Space Administration } \\
\text { Washington, DC 20546-0001 }\end{array}$}} & $\begin{array}{l}\text { 10. SPONSORING/MONITOR'S } \\
\text { ACRONYM(S) } \\
\text { NASA }\end{array}$ \\
\hline & & $\begin{array}{l}\text { 11. SPONSORING/MONITORING } \\
\text { REPORT NUMBER } \\
\text { NASA/TM-2010-216344 }\end{array}$ \\
\hline \multicolumn{3}{|c|}{$\begin{array}{l}\text { 12. DISTRIBUTIONIAVAILABILITY STATEMENT } \\
\text { Unclassified-Unlimited } \\
\text { Subject Categories: } 01,02 \text {, and } 03 \\
\text { Available electronically at http://gltrs.grc.nasa.gov } \\
\text { This publication is available from the NASA Center for AeroSpace Information, 443-757-5802 }\end{array}$} \\
\hline
\end{tabular}

\section{SUPPLEMENTARY NOTES}

Published in AIAA Journal of Aircraft, Volume 47, Number 1, January-February 2010, pp. 240-254.

\section{ABSTRACT}

The simulation of ice accretion on a wing or other surface is often required for aerodynamic evaluation, particularly at small scale or lowReynolds number. While there are commonly accepted practices for ice simulation, there are no established and validated guidelines. The purpose of this article is to report the results of an experimental study establishing a high-fidelity, full-scale, iced-airfoil aerodynamic performance database. This research was conducted as a part of a larger program with the goal of developing subscale aerodynamic simulation methods for iced airfoils. Airfoil performance testing was carried out at the ONERA F1 pressurized wind tunnel using a 72-in. (1828.8-mm) chord NACA 23012 airfoil over a Reynolds number range of 4.5×106 to 16.0×106 and a Mach number range of 0.10 to 0.28 . The high-fidelity, ice-casting simulations had a significant impact on the aerodynamic performance. A spanwise-ridge ice shape resulted in a maximum lift coefficient of 0.56 compared to the clean value of 1.85 at $R e=15.9 \times 106$ and $\mathrm{M}=0.20$. Two roughness and streamwise shapes yielded maximum lift values in the range of 1.09 to 1.28 , which was a relatively small variation compared to the differences in the ice geometry. The stalling characteristics of the two roughness and one streamwise ice simulation maintained the abrupt leading-edge stall type of the clean NACA 23012 airfoil, despite the significant decrease in maximum lift. Changes in Reynolds and Mach number over the large range tested had little effect on the iced-airfoil performance.

\section{SUBJECT TERMS}

Aircraft icing; Airfoil; Aerodynamic performance

\begin{tabular}{|c|c|c|c|c|c|}
\hline \multicolumn{3}{|c|}{ 16. SECURITY CLASSIFICATION OF: } & \multirow{2}{*}{$\begin{array}{l}\text { 17. LIMITATION OF } \\
\text { ABSTRACT } \\
\text { UU }\end{array}$} & \multirow{2}{*}{$\begin{array}{l}\text { 18. NUMBER } \\
\text { OF } \\
\text { PAGES } \\
27\end{array}$} & \multirow{2}{*}{$\begin{array}{l}\text { 19a. NAME OF RESPONSIBLE PERSON } \\
\text { STI Help Desk (email:help@sti.nasa.gov) } \\
\text { 19b. TELEPHONE NUMBER (include area code) } \\
\text { 443-757-5802 }\end{array}$} \\
\hline $\begin{array}{l}\text { a. REPORT } \\
\text { U }\end{array}$ & $\begin{array}{l}\text { b. ABSTRACT } \\
\text { U }\end{array}$ & $\begin{array}{l}\text { c. THIS } \\
\text { PAGE } \\
\text { U }\end{array}$ & & & \\
\hline
\end{tabular}



